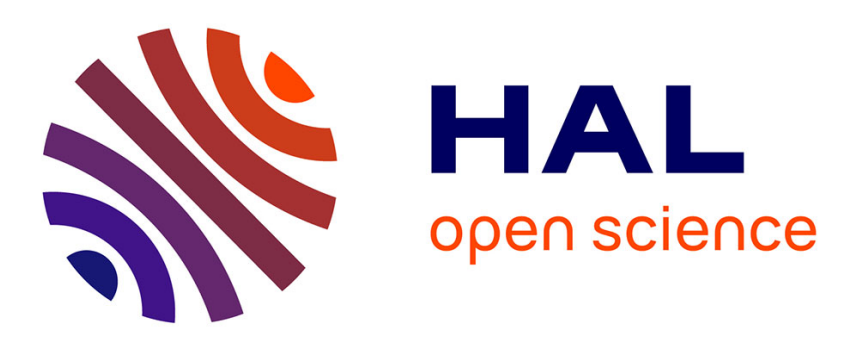

\title{
Enhanced vertical mixing in coastal upwelling systems driven by diurnal-inertial resonance: numerical experiments
}

Giles Fearon, Steven Herbette, Jennifer Veitch, Gildas Cambon, Andrew J Lucas, Florian Lemarié, Marcello Vichi

\section{To cite this version:}

Giles Fearon, Steven Herbette, Jennifer Veitch, Gildas Cambon, Andrew J Lucas, et al.. Enhanced vertical mixing in coastal upwelling systems driven by diurnal-inertial resonance: numerical experiments. Journal of Geophysical Research. Oceans, 2020, 125 (9), pp.e2020JC016208. 10.1029/2020JC016208 . hal-02544118v2

\author{
HAL Id: hal-02544118 \\ https://hal.inria.fr/hal-02544118v2
}

Submitted on 16 Apr 2020

HAL is a multi-disciplinary open access archive for the deposit and dissemination of scientific research documents, whether they are published or not. The documents may come from teaching and research institutions in France or abroad, or from public or private research centers.
L'archive ouverte pluridisciplinaire HAL, est destinée au dépôt et à la diffusion de documents scientifiques de niveau recherche, publiés ou non, émanant des établissements d'enseignement et de recherche français ou étrangers, des laboratoires publics ou privés. 


\section{Enhanced vertical mixing in coastal upwelling systems driven by diurnal-inertial resonance: numerical experiments}

Giles Fearon ${ }^{1,3}$, Steven Herbette ${ }^{2}$, Jennifer Veitch ${ }^{3,7}$, Gildas Cambon ${ }^{2}$, Andrew J. Lucas ${ }^{4}$, Florian Lemarié ${ }^{5}$, Marcello Vichi ${ }^{1,6}$

${ }^{2}$ Laboratoire d'Océanographie Physique et Spatiale (LOPS), IUEM, Univ. Brest - CNRS - IRD - Ifremer, Brest, France

${ }^{3}$ South African Environmental Observation Network, Egagasini Node, Cape Town, South Africa

${ }^{4}$ Scripps Institution of Oceanography, University of California, San Diego, La Jolla, CA, USA

${ }^{5}$ Univ Grenoble Alpes, Inria, CNRS, Grenoble INP, LJK, Grenoble, France

${ }^{6}$ Marine and Antarctic Research centre for Innovation and Sustainability (MARIS), University of Cape

Town, Rondebosch, South Africa

${ }^{7}$ Nansen-Tutu Centre, Marine Research Institute, Department of Oceanography, University of Cape Town,

South Africa

\section{Key Points:}

- Land-sea breeze driven vertical mixing is studied using a 1D model including the land boundary effect

- The land boundary effect dampens vertical mixing, particularly when bottom friction is non-negligible

- The diurnal anticyclonic rotary component of the wind stress provides a diagnostic for diapycnal mixing

Corresponding author: Giles Fearon, gfearon11@gmail.com 


\section{Abstract}

The land-sea breeze is resonant with the inertial response of the ocean at the critical latitude of $30^{\circ} \mathrm{N} / \mathrm{S}$. 1D-vertical numerical experiments were undertaken to study the key drivers of enhanced diapycnal mixing in coastal upwelling systems driven by diurnal-inertial resonance near the critical latitude. The effect of the land boundary was implicitly included in the model through the 'Craig approximation' for first order cross-shore surface elevation gradient response. The model indicates that for shallow water depths $(<\sim 100 \mathrm{~m})$, bottom shear stresses must be accounted for in the formulation of the 'Craig approximation', as they serve to enhance the cross-shore surface elevation gradient response, while reducing shear and mixing at the thermocline. The model was able to predict the observed temperature and current features during an upwelling/mixing event in $60 \mathrm{~m}$ water depth in St Helena Bay $\left(\sim 32.5^{\circ} \mathrm{S}\right.$, southern Benguela), indicating that the locally forced response to the land-sea breeze is a key driver of diapycnal mixing over the event. Alignment of the sub-inertial Ekman transport with the surface inertial oscillation produces 'shear spikes' at the diurnal-inertial frequency, however their impact on mixing is secondary when compared with the diurnal-inertial resonance phenomenon. The amplitude of the diurnal anticlockwise rotary component of the wind stress represents a good diagnostic for the prediction of diapycnal mixing due to diurnal-inertial resonance. The local enhancement of this quantity over St Helena Bay provides strong evidence for the importance of the land-sea breeze in contributing to primary production in this region through nutrient enrichment of the surface layer.

\section{Plain Language Summary}

Winds near the coast often have a daily cycle known as the land-sea breeze. Near latitudes of $30^{\circ} \mathrm{N} / \mathrm{S}$ ubiquitous rotating ocean currents also have a daily frequency and therefore become enhanced by daily winds at these latitudes. The ocean currents result in vertical mixing of subsurface and surface water layers, bringing subsurface nutrients to the surface where they stimulate phytoplankton growth. In this study we use a simple model of the ocean (comprised of the vertical dimension only) to study the key drivers of vertical mixing due to the land-sea breeze. We show how vertical mixing is reduced in shallow water $(<\sim 100 \mathrm{~m})$ near the coast, where currents are slowed down by friction at the seabed. We find that vertical mixing can be predicted by a parameter computed from wind speed and direction over time. This parameter is shown to be enhanced over St Helena Bay on the west 
coast of South Africa, where phytoplankton blooms are known to be particularly prevalent. The results suggest that the land-sea breeze is likely to be an important contributor to phytoplankton bloom development in this region. Similar processes are likely to be at play in other coastal regions where phytoplankton productivity is enhanced.

\section{Introduction}

The four major Eastern Boundary Upwelling Systems (EBUS) are regions along the eastern land boundaries of the Pacific and Atlantic Oceans where the upwelling of cold nutrient-rich waters to the euphotic zone promotes phytoplankton growth. Although they account for less than $1 \%$ of the ocean surface area, EBUS are responsible for about a third of global primary productivity (Pauly \& Christensen, 1995). Sustained alongshore equatorward winds (driving Ekman transport) and wind stress curl corresponding to the wind drop-off at the coast (driving Ekman suction) are the primary drivers of upwelling, while retention mechanisms during wind relaxation are important for the accumulation of high biomass coastal blooms (G. Pitcher et al., 2010). A feature common to all EBUS is the land-sea breeze phenomenon, characterised by pronounced diurnal wind variability driven by differential heating over the land and the ocean (Gille, 2003, 2005). As Ekman dynamics responds to wind variability with a time scale in the order of days, diurnal wind variability over EBUS is often assumed to be of low importance for understanding the physical and biogeochemical processes of these systems relative to sub-inertial winds. The land-sea breeze has however been identified as a mechanism for contributing to nutrient enrichment of the surface layer through diapycnal mixing (Aguiar-González et al., 2011; Lucas et al., 2014). This paper further explores the contribution of the land-sea breeze to driving vertical mixing and consequent diapycnal nutrient flux in coastal upwelling systems.

The response of the ocean to a surface wind stress takes the form of both rotary and nonrotary components (Ekman, 1905), with Ekman dynamics corresponding to the non-rotary component. The rotary component refers to inertial oscillations, which can be described as anticyclonic circular motions with a frequency equal to the Coriolis parameter $f=2 \Omega \sin \phi$, where $\Omega$ is the angular rotation of the earth, and $\phi$ is the latitude. In the case of a uniform wind stress, a forcing duration of half the inertial period (less than one day at all latitudes by definition) is optimal for imparting energy into the inertial response (R. Pollard, 1970). The most efficient way of imparting energy into surface mixed layer inertial currents is in the form of an anticyclonically rotating wind stress with a frequency $\omega$ equal to the inertial 
frequency $f$, as in this case the wind stress and surface current vectors are always aligned (R. Pollard \& Millard, 1970; D'Asaro, 1985; Alford, 2001). Near latitudes of 30 N/S the inertial frequency is diurnal, leading to resonance between the land-sea breeze and the inertial response; a phenomenon known as diurnal-inertial resonance (Craig, 1989; Simpson et al., 2002). This implies that even low amplitude diurnal wind variability can give rise to significant amplitude inertial oscillations at these latitudes.

In proximity to a land boundary, a two layer vertical current structure is commonly observed, with a $180^{\circ}$ phase shift between surface and subsurface layers (e.g. Millot \& Crépon, 1981; Shearman, 2005; Simpson et al., 2002; Lucas et al., 2014). This phenomenon has been explained using an analytical model for the first order coast-normal surface elevation gradient response (termed the 'Craig approximation') imposed by the barotropic no-flow condition perpendicular to the land boundary (Craig, 1989; Simpson et al., 2002). It should however be highlighted that the two layer current structure produced in this way is not a true first baroclinic mode, but rather the superposition of the forced surface mixed layer response and the opposing barotropic pressure gradient, with a net effect of zero depthaveraged coast-normal transport. The two layer current structure can even be produced in a vertically homogeneous water column (Pettigrew, 1980; S. Chen et al., 2017). The presence of a land boundary does however introduce horizontal convergence and divergence of the forced surface mixed layer response, leading to inertial pumping of the pycnocline and the generation of propagating near-inertial internal waves (e.g. Alford et al., 2016; Kelly, 2019). The first baroclinic mode internal wave response can be difficult to separate from the forced response due to their similar vertical current structures and frequencies.

An important consequence of the vertical structure of inertial currents is the enhancement of shear at the pycnocline, leading to turbulence and diapycnal mixing. Observations of wind-driven inertial oscillations in shallow stratified shelf seas have been shown to produce bursts of enhanced shear at the inertial frequency, termed 'shear spikes', which promote vertical mixing and deepening of the thermocline (Burchard \& Rippeth, 2009; Lincoln et al., 2016). The analytical shear production theory of Burchard and Rippeth (2009) has been shown to provide a good explanation for these observations. Such 'shear spikes' have been further shown to contribute significantly to surface nutrient availability and consequently primary productivity in shelf seas (Williams et al., 2013). The theory of Burchard and Rippeth (2009) is however yet to be applied in the context of diurnal-inertial resonance. 

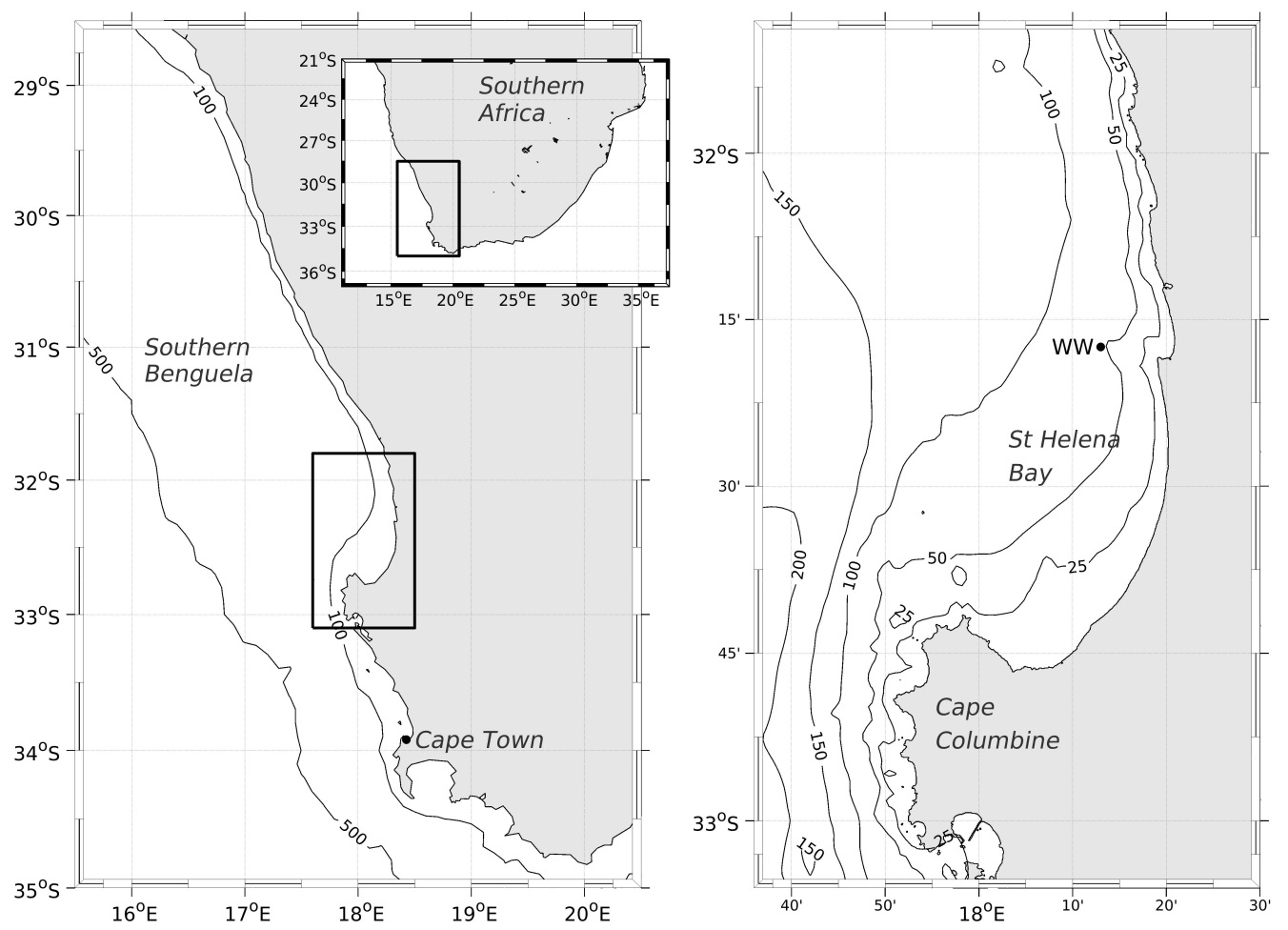

Figure 1. Locality map for St Helena Bay and the Lucas et al. (2014) offshore mooring (labelled 'WW'). Bathymetric contours were derived from digital navigational charts for the region provided by the Hydrographer of the SA Navy.

Perhaps the clearest demonstration of inertial oscillation-driven mixing and consequent enhancement of primary productivity in upwelling systems are the nearshore measurements of Lucas et al. (2014) in St Helena Bay, located in the Southern Benguela Upwelling System. Data from the mooring in $\sim 60 \mathrm{~m}$ water depth (Figure 1) are revisited in this study. Analysis of land-based wind measurements indicate strong diurnal wind variability, and at a latitude of $\sim 32.5^{\circ} \mathrm{S}$ (inertial period of $\sim 22 \mathrm{hr}$ ), diurnal-inertial resonance leads to the ubiquitous presence of energetic inertial oscillations (surface amplitude $>0.5 \mathrm{~m} / \mathrm{s}$ ) within the bay (Fawcett et al., 2008; Lucas et al., 2014). St Helena Bay is also one of the most productive regions of the Benguela Upwelling System, as evidenced by a clear peak in coastal chlorophyll derived from satellite data (Demarcq et al., 2007). It is therefore an ideal location for studying inertial oscillation-driven diapycnal mixing and implications for phytoplankton phenomenology in coastal upwelling systems.

As inertial oscillations have been observed to be tightly coupled to the local wind forcing, salient features of the observations have been reasonably reproduced by linearly damped 
slab models of the surface layer (e.g. R. Pollard \& Millard, 1970; R. T. Pollard, 1980; Alford, 2001; Jarosz et al., 2007). Such models however do not account for the deepening of the surface layer due to diapycnal mixing and explicitly ignore subsurface effects. One-dimensional (1D) models have been used to simulate inertial oscillation-driven vertical mixing in response to local wind forcing, but are limited by the exclusion of propagating near-inertial internal waves which can be an important source of turbulence and mixing (Xing et al., 2004; Zhang et al., 2010). Hyder et al. (2011) showed that a 1D model forced with the 'Craig approximation' is able to qualitatively reproduce the $180^{\circ}$ phase shift between surface and subsurface layers off the Namibian coastline in $175 \mathrm{~m}$ water depth.

In this paper we carry out 1D-vertical numerical experiments with the aim of elucidating diapycnal mixing dynamics of a coastal system characterised by two layers separated by strong stratification and forced by a land-sea breeze near the critical latitude of $30^{\circ} \mathrm{N} / \mathrm{S}$. Vertical mixing is parameterised in the model using the $k$ - $\varepsilon$ turbulent closure scheme (Umlauf \& Burchard, 2003, 2005). The use of a 1D model precludes the internal wave response, allowing us to isolate the impact of the forced response. The no-flow condition perpendicular to the land boundary is included in the model through the 'Craig approximation', although the formulation presented in Simpson et al. (2002) has been extended here to include bottom friction terms. The bulk shear production theory of Burchard and Rippeth (2009) has been compared with both the model and observations, providing a useful lens through which to interpret the event-scale mixing dynamics. Diapycnal mixing has been further diagnosed through the initialisation of the model with a passive tracer below the surface layer, used to represent a reservoir of subsurface nutrients. The model is used to undertake a series of experiments to explore the physical processes and key drivers of enhanced vertical mixing in coastal upwelling systems due to diurnal-inertial resonance. Comparison of the model with the observations of Lucas et al. (2014) provides insight into the strengths and limitations of the model. Implications of the model results for surface layer nutrient enhancement in St Helena Bay and other EBUS is then inferred.

\section{Methods}

\subsection{In-situ observations}

This paper makes use of in-situ observations from Wirewalker wave-powered profilers (Rainville \& Pinkel, 2001; Pinkel et al., 2011) and bottom-mounted Acoustic Doppler 
Current Profilers (ADCP), providing concurrent high-frequency nearshore measurements of velocity, temperature, salinity, dissolved oxygen and chlorophyll fluorescence within St Helena Bay. The full dataset is described in detail in Lucas et al. (2014), although only the velocity and temperature data from the offshore mooring ( $\sim 60 \mathrm{~m}$ water depth) over the February-April 2011 deployment are revisited in this paper (see Figure 1). The vertical resolution of the ADCP velocity data is $1 \mathrm{~m}$ while temperature is available at $0.25 \mathrm{~m}$ intervals. All measurements presented in this paper were filtered in time to provide a two hour running mean at $30 \mathrm{~min}$ intervals, sufficient for analysing processes at the diurnal-inertial frequency of interest for this study. The observations are compared with the model over a 7 day event in March 2011, having been identified in Lucas et al. (2014) as a period which clearly demonstrates the response of a highly stratified two layer system to the onset of upwelling favourable winds with an anticlockwise sense of rotation.

\subsection{Atmospheric forcing}

Atmospheric forcing data for this study have been obtained from a Weather Research and Forecasting (WRF) model configuration developed by the Climate Systems Analysis Group (CSAG) at the University of Cape Town (UCT). The atmospheric simulation forms part of the Wind Atlas for South Africa (WASA) project and has been validated against a number of land-based weather stations, including one deployed at the southern end of St Helena Bay over a three year period (Lennard et al., 2015). Model output is available on a $\sim 3 \mathrm{~km}$ resolution horizontal grid at hourly intervals for the period November 2005 to October 2013 (8 years). Surface wind stresses used in this study have been derived from the CSAG $10 \mathrm{~m}$ wind speeds using the empirical drag formulation of Large and Pond (1981).

Rotary analyses have been carried out on the wind stress data to extract the diurnal anticyclonic (anticlockwise in the southern hemisphere) rotary component of the wind stress $\left(\tau^{a c}\right)$. Near latitudes of $30^{\circ} \mathrm{N} / \mathrm{S}, \tau^{a c}$ represents the component of the wind stress which rotates in the same direction and frequency as the inertial oscillation, and so energy flux from the wind is at all times positive (in the absence of background currents).

The complex function $\tau^{a c}=\tau^{a c 0} e^{i\left(\omega t+\phi^{a c}\right)}$ defines a wind stress vector rotating in an anticlockwise direction with a diurnal frequency $\omega$, a constant amplitude $\tau^{a c 0}$, and a phase angle $\phi^{a c}$. The purpose of the rotary analysis is to compute the parameters $\tau^{a c 0}$ and $\phi^{a c}$ from the time-series of wind stress components. To do this, the wind ellipse parameters 

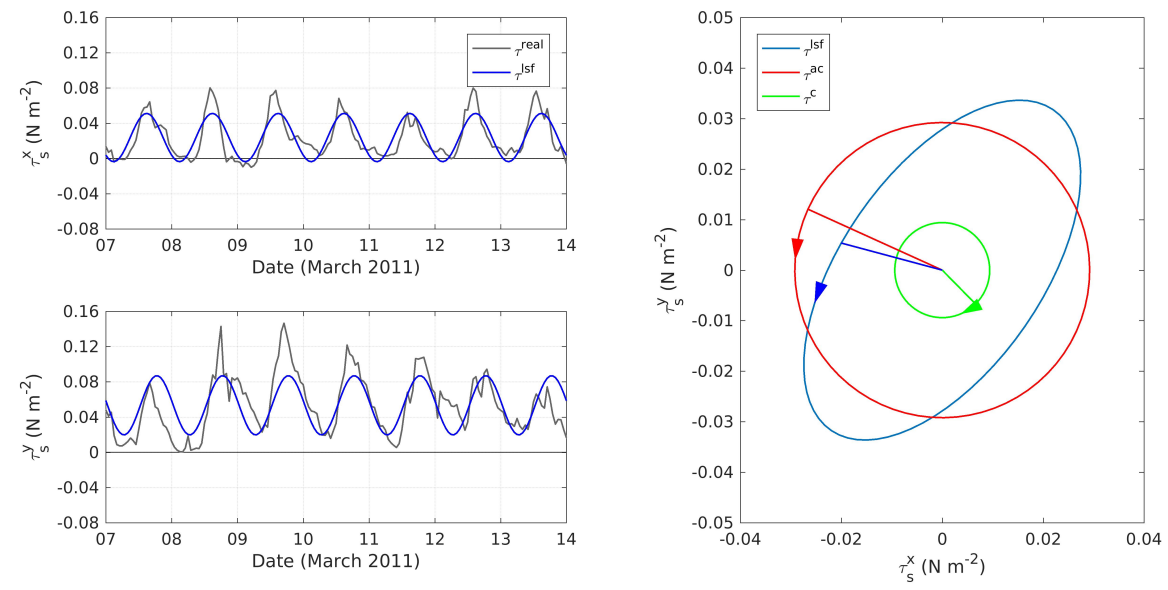

Figure 2. Rotary analysis of wind stress over an example

7 day period used to carry out realistically forced $1 \mathrm{D}$ simulations. The blue time-series are the diurnal least squares fit curves to the wind stress components which sweep the blue ellipse $\left(\tau^{l s f}\right)$. The ellipse is decomposed into clockwise $\left(\tau^{c}\right)$ and anticlockwise $\left(\tau^{a c}\right)$ rotating components. The radial lines indicate the associated phase angles.

were firstly determined via a diurnal least squares fit (lsf) harmonic analysis on each of the wind stress components, from which the parameters $\tau^{a c 0}$ and $\phi^{a c}$ were extracted using standard conversion techniques provided in the tidal_ellipse Matlab package (Xu, 2002). As the periodicity of the wind stress varies over time (unlike a tidal constituent whose phase and amplitude are constant), the result of the rotary analysis is particularly sensitive to the time window over which the analysis is carried out. Longer windows lead to smaller amplitude rotary components and a poorer fit to inter-diurnal variability. All rotary analyses presented in this paper have been carried out on 7 day windows, representative of the time-scale of individual upwelling events. The methodology described above is depicted in Figure 2 for the period used to compare observed event-scale mixing dynamics with the model. The WRF model output was extracted at the location of the observations (Figure 1), providing the wind stress and heat flux input for the ocean model.

\subsection{Ocean model}

The ocean model employed in this study is a standalone 1D version of the Coastal and Regional Ocean COmmunity model (CROCO) (http://www.croco-ocean.org/), an ocean modelling system built upon ROMS_AGRIF (Shchepetkin \& McWilliams, 2005), in 
which we retain the horizontal pressure gradient term normal to the coast. The 1D-vertical model solves the following equations for the horizontal velocity components $(u, v)$, active tracers temperature $(T)$ and salinity $(S)$, and a passive tracer $(C)$ used to represent the concentration of subsurface nutrients:

$$
\begin{aligned}
\frac{\partial u}{\partial t} & =f v+\frac{\partial}{\partial z}\left(K_{m} \frac{\partial u}{\partial z}\right)-g \frac{\partial \eta}{\partial x}, \\
\frac{\partial v}{\partial t} & =-f u+\frac{\partial}{\partial z}\left(K_{m} \frac{\partial v}{\partial z}\right), \\
\frac{\partial T}{\partial t} & =\frac{\partial}{\partial z}\left(K_{s} \frac{\partial T}{\partial z}\right)+\frac{1}{\rho_{0} C_{p}}\left(-\frac{\partial Q_{s}}{\partial z}\right), \\
\frac{\partial S}{\partial t} & =\frac{\partial}{\partial z}\left(K_{s} \frac{\partial S}{\partial z}\right), \\
\frac{\partial C}{\partial t} & =\frac{\partial}{\partial z}\left(K_{s} \frac{\partial C}{\partial z}\right),
\end{aligned}
$$

where $K_{m}$ and $K_{s}$ are the turbulent viscosity and diffusivity, respectively, $\eta$ is the surface elevation, $f$ is the Coriolis parameter, $Q_{s}$ is a downward solar flux, $\rho_{0}$ is the reference density $\left(1024 \mathrm{~kg} \mathrm{~m}^{-3}\right)$, and $C_{p}$ is the specific heat coefficient $\left(3985 \mathrm{~J} \mathrm{~kg}^{-1} \mathrm{~K}^{-1}\right) . K_{m}$ and $K_{s}$ are computed using a $k-\varepsilon$ turbulent closure parameterisation within the Generic Length-Scale (GLS) formulation (Umlauf \& Burchard, 2003, 2005, and Appendix A for a description of the implementation in CROCO). Minimum values for $K_{m}$ and $K_{s}$ are taken as $10^{-4} \mathrm{~m}^{2} \mathrm{~s}^{-1}$ and $10^{-5} \mathrm{~m}^{2} \mathrm{~s}^{-1}$, respectively, representing background values for turbulence and mixing. The model is completed by the following top $(z=0)$ and bottom $(z=-H)$ boundary conditions for velocity components:

$$
\begin{aligned}
\rho_{0} K_{m} \frac{\partial}{\partial z} \vec{u}(0, t) & =\overrightarrow{\tau_{s}}, \\
K_{m} \frac{\partial}{\partial z} \vec{u}(-H, t) & =\overrightarrow{\tau_{b}}=C_{d}|\vec{u}(-H, t)| \vec{u}(-H, t),
\end{aligned}
$$

where the surface stress $\overrightarrow{\tau_{s}}=\left(\tau_{s}^{x}, \tau_{s}^{y}\right)$ is specified analytically or through external data, while the bottom stress $\overrightarrow{\tau_{b}}=\left(\tau_{b}^{x}, \tau_{b}^{y}\right)$ is determined from the shown quadratic drag law with a drag coefficient $\left(C_{d}\right)$ defined as:

$$
C_{d}=\left(\frac{\kappa}{\ln \left(z_{b} / z_{0}\right)}\right)^{2}
$$


where $\kappa$ is the von Kármán constant $(0.4), z_{0}$ is the bottom roughness length parameter (taken as $0.1 \mathrm{~m}$ ) and $z_{b}$ is the thickness of the bottom layer of the model. Upper and lower limits for $C_{d}$ were applied as 0.02 and 0.0025 , respectively. The surface boundary conditions for the tracers are:

$$
\begin{aligned}
\rho_{0} C_{p} K_{s} \frac{\partial}{\partial z} T(0, t) & =-\left(Q_{0}(t)-Q_{s}(0, t)\right) \\
K_{s} \frac{\partial}{\partial z} S(0, t) & =0 \\
K_{s} \frac{\partial}{\partial z} C(0, t) & =0
\end{aligned}
$$

with $Q_{0}(t)$ the net heat flux and $Q_{s}(0, t)$ the surface downward solar radiation both extracted either from WRF model outputs or set analytically (see Section 2.5). The penetration of downward solar radiation in the vertical is parameterized using a standard Jerlov law. We assume zero water flux at the surface since temperature is the major driver for density in the region. The bottom boundary conditions for tracers are simply $K_{s} \frac{\partial}{\partial z} T(-H, t)=$ $K_{s} \frac{\partial}{\partial z} S(-H, t)=K_{s} \frac{\partial}{\partial z} C(-H, t)=0$. The model is discretised using an implicit Euler scheme in time and a standard second-order finite-volume approach in space consistent with the CROCO discretisation of vertical mixing terms. Because the Brunt-Väisälä frequency is required by the $k$ - $\varepsilon$ turbulent scheme an equation of state for seawater must be added to the system of equations (1). For the present study a nonlinear equation of state adapted from Jackett and Mcdougall (1995) is used.

\section{4 'Craig approximation'}

The effect of the land boundary (assumed to be orientated along the $y$-axis for the purposes of this study) is implicitly included in the model through the surface elevation gradient term $\left(\frac{\partial \eta}{\partial x}\right)$ in Equation 1a, being a user-specified input to the model. This term has been determined according to Craig (1989) and Simpson et al. (2002), however here we extend the formulation to include the effect of bottom friction. The governing equations for depth-averaged velocity components $(U, V)$ can be written as:

$$
\begin{gathered}
\frac{\partial U}{\partial t}=f V-g \frac{\partial \eta}{\partial x}+\frac{\tau_{s}^{x}}{\rho H}-\frac{\tau_{b}^{x}}{H}, \\
\frac{\partial V}{\partial t}=-f U-g \frac{\partial \eta}{\partial y}+\frac{\tau_{s}^{y}}{\rho H}-\frac{\tau_{b}^{y}}{H},
\end{gathered}
$$


where $H$ is the water depth. If $U$ and $V$ are taken to represent the cross-shore and alongshore depth-averaged velocity components, respectively, then the condition of zero depth-average flow perpendicular to the coast dictates that $U=0$ and therefore $\frac{\partial U}{\partial t}=0$. Assuming zero alongshore pressure gradients $\left(\frac{\partial \eta}{\partial y}=0\right)$ and a wave solution for the alongshore depthaveraged velocity $\left(\frac{\partial V}{\partial t}=-i \omega V\right)$, then Equation $5 \mathrm{~b}$ can be recast as $V=\frac{i}{\omega H}\left(\frac{\tau_{s}^{y}}{\rho}-\tau_{b}^{y}\right)$. Substitution of $V$ into Equation 5a yields the surface elevation gradient response:

$$
\frac{\partial \eta}{\partial x}=\frac{\tau_{s}^{x}+i(f / \omega) \tau_{s}^{y}}{\rho g H}-\frac{\tau_{b}^{x}+i(f / \omega) \tau_{b}^{y}}{g H} .
$$

The wind stress terms $\left(\frac{\tau_{s}^{x}+i(f / \omega) \tau_{s}^{y}}{\rho g H}\right)$ correspond to the 'Craig approximation' as presented in Simpson et al. (2002). As we aim to force the model with realistic wind stresses, and do not have an a priori analytical solution for bottom shear stresses, the complex terms in Equation 6 preclude an analytical solution for $\frac{\partial \eta}{\partial x}$. The assumption of diurnal variability as the dominant signal in both surface and bottom stress is however made, being valid in the case of land-sea breeze forcing near the critical latitude, as the periodicity in both the forcing and the ocean response can be assumed to be near-diurnal. In the case of periodically oscillating wind and bottom stress, the complex terms in Equation 6 correspond to a $\frac{\pi}{2}$ phase shift in these variables. We therefore assign the terms $i \tau_{s}^{y}$ and $i \tau_{b}^{y}$ to be equal to the values of $\tau_{s}^{y}$ and $\tau_{b}^{y}$ at a time 6 hours prior to the given time-step, respectively.

\subsection{Model configuration}

The number of vertical layers was assigned to be equal to the water depth in metres, ensuring the same vertical grid resolution for all simulations. A time-step of $10 \mathrm{~s}$ was used to integrate the model solution over a period of 7 days from initialisation, typical of the time-scale of upwelling events. Model output at 30 min intervals was filtered in time to provide a two hour running mean at each time-step, consistent with the processing of observations. Both analytical and realistic model configurations were employed. Simulations were initialised from rest using a constant salinity of 35 and a temperature profile defined either analytically or from observations, as described below.

The purpose of the analytical model configurations was to explore the physical processes and key drivers of enhanced vertical mixing in a two layer coastal system due to diurnal-inertial resonance. The initial temperature profile for these experiments was speci- 
fied according to a hyperbolic tangent function as follows:

$$
T(z)=10+\Delta T / 2(1-\tanh (((z-\mathrm{MLD}) / 3)),
$$

where $\Delta T$ is the difference between surface and subsurface temperatures and MLD the initial mixed layer depth, corresponding to the depth of maximum stratification. The resulting profile increases from $10^{\circ} \mathrm{C}$ in the subsurface to a specified surface layer temperature. Higher $\Delta T$ 's imply higher levels of stratification. Surface wind stress forcing took the form of constant amplitude rotating winds at a diurnal frequency (representative of the land-sea breeze), constant winds (representative of a mean alongshore wind), or a combination of the two. Surface heat fluxes were ignored in the analytical configurations.

A realistic model configuration was used to compare the model with the observations of Lucas et al. (2014) over the period 7-14 March 2011. The initial temperature profile was interpolated directly from the observations. Surface wind stress forcing took the form of both realistic wind stresses derived from the WRF model output as well as the diurnal anticlockwise rotary component of the wind stress $\left(\tau^{a c}\right)$, as shown in Figure 2. Surface heat flux forcing was estimated as the net heat flux derived from short and long wave radiation output from the WRF model, ignoring contributions of latent and sensible heat. This yielded daily peaks in positive heat flux of approximately $800 \mathrm{~W} / \mathrm{m}^{2}$ over the simulation period.

\subsection{Diapycnal mixing diagnostics}

As this paper focusses on diapycnal mixing at the interface of a two layer system, we use the bulk shear vector $\vec{S}=\left(S_{u}, S_{v}\right)$ as defined by Burchard and Rippeth (2009) as an indicator of shear between the surface and bottom layers:

$$
S_{u}=\frac{u_{s}-u_{b}}{1 / 2 H}, \quad S_{v}=\frac{v_{s}-v_{b}}{1 / 2 H},
$$

where $\overrightarrow{u_{s}}=\left(u_{s}, v_{s}\right)$ and $\overrightarrow{u_{b}}=\left(u_{b}, v_{b}\right)$ are the depth-averaged velocity vectors for the surface and bottom layers, respectively. Based on the one-dimensional momentum equations for a two layer system, Burchard and Rippeth (2009) derived the dynamical equation for bulk shear squared $\left(S^{2}=S_{u}^{2}+S_{v}^{2}\right)$, used in this paper as a tool for interpreting event-scale mixing dynamics: 


$$
\frac{\partial S^{2}}{\partial t}=\frac{4}{H} \vec{S} \cdot\left(\frac{\overrightarrow{\tau_{s}}}{H_{s}}+\frac{\overrightarrow{\tau_{b}}}{H_{b}}\right)-c_{i} \frac{H^{2}}{H_{s} H_{b}} S^{3}
$$

where $H_{s}$ and $H_{b}$ are the depths of the surface and subsurface layers, respectively, $\overrightarrow{\tau_{s}}=$ $\left(\tau_{s}^{x}, \tau_{s}^{y}\right)$ is the surface shear stress vector, $\overrightarrow{\tau_{b}}=\left(\tau_{b}^{x}, \tau_{b}^{y}\right)$ is the bottom shear stress vector and $c_{i}$ is the interfacial drag coefficient. In this study $H_{s}$ is computed from a defined isotherm (varying depending on the configuration), used as a proxy for the interface between the upper and lower layers. $c_{i}$ may be roughly estimated as follows:

$$
c_{i}=K_{m} \frac{4 S_{i}}{H^{2} S^{2}},
$$

where $S_{i}$ is the interfacial shear estimated locally at the interface of the two layers (Burchard \& Rippeth, 2009). Estimates of $c_{i}$ from the model output were computed using the $K_{m}$ returned from the $k-\varepsilon$ turbulent closure scheme, while a constant value of $K_{m}=1.5 \times$ $10^{-4} \mathrm{~m}^{2} \mathrm{~s}^{-1}$ was adopted for processing of the observations. Equation 9 dictates that bulk shear is generated when the bulk shear vector is in alignment with the surface and/or bottom shear stress vectors. The last term on the right hand side of Equation 9 represents the loss of bulk shear due to interfacial mixing between the two layers. In this paper we compare the theoretical bulk shear production of Equation 9 with that computed directly from the model output and from the observations. $\frac{\partial S^{2}}{\partial t}$ from both the model output and observations is computed as the gradient of a least squares fit straight line for data within a 2 hour window of each 30 min time-step.

The quantification of diapycnal mixing over the simulations was further aided by initialising the model with a passive tracer $(C)$ below the surface mixed layer, representing a reservoir of subsurface nutrients. The cumulative diapycnal mixing of the passive tracer to the surface layer has been computed by integrating the passive tracer concentration multiplied by the grid cell height $(\Delta z)$ over the surface layer:

$$
C_{s}=\sum_{z=-H_{s}}^{z=0} C \times \Delta z
$$

$C_{s}$ provides an indicator of enhanced availability of surface layer nutrients for primary productivity. 

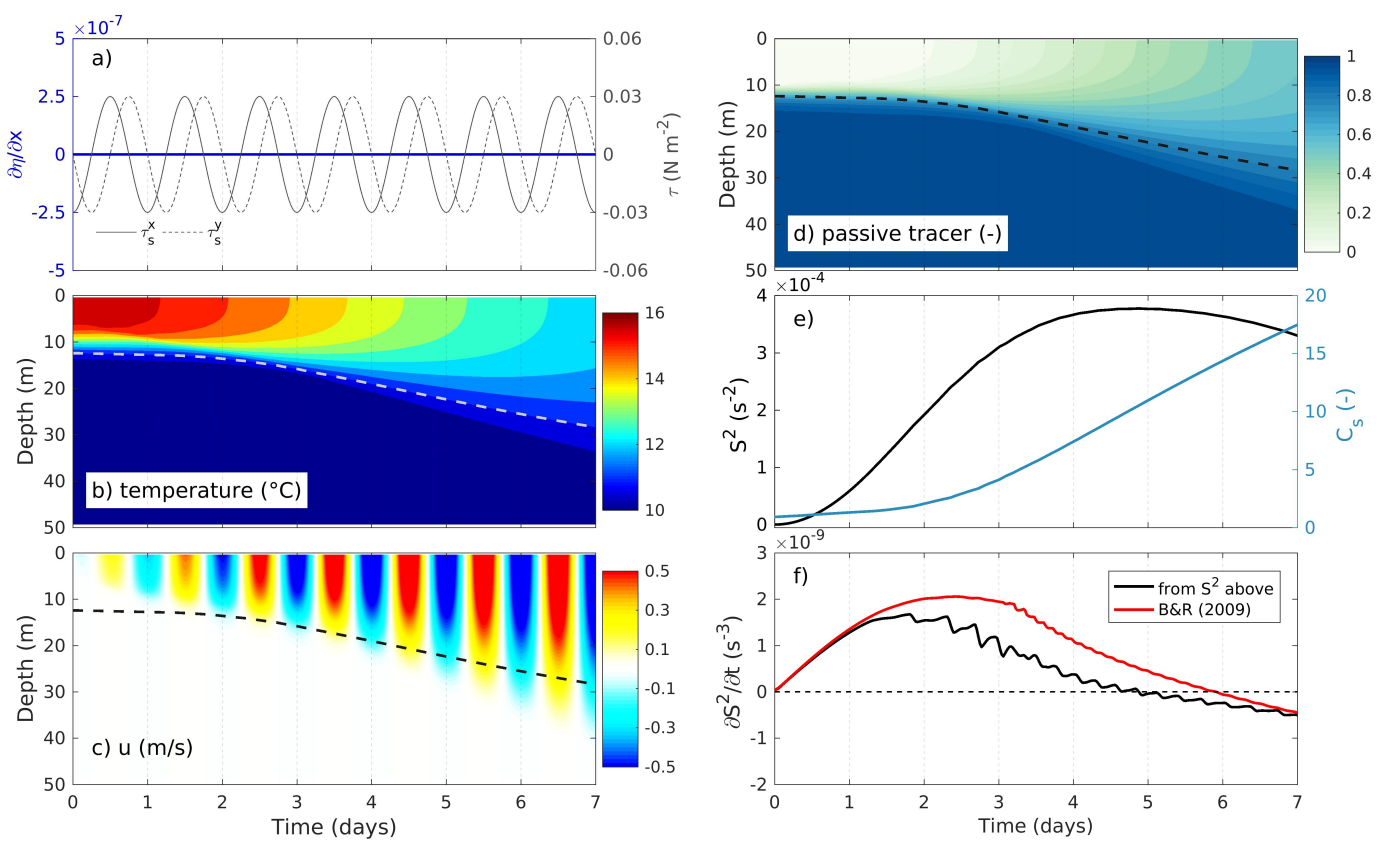

Figure 3. Open Ocean Case. (a) Wind stress components $\left(\tau_{s}^{x}, \tau_{s}^{y}\right)$ and cross-shore surface elevation gradient forcing $(\partial \eta / \partial x)$; (b) Vertical profile of temperature (the dotted line denotes the $11^{\circ} \mathrm{C}$ isotherm used as a proxy for the interface between the upper and lower layers); (c) Vertical profile of the cross-shore component of velocity $(u)$; (d) Vertical profile of passive tracer concentration; (e) Bulk shear $\left(S^{2}\right)$ and passive tracer integrated over the surface layer $\left(C_{s}\right)$; (f) Bulk shear production $\left(\frac{\partial S^{2}}{\partial t}\right)$ computed from both the model output and from the theory of Burchard and Rippeth (2009) (Equation 9). Results are computed from a 7 day integration of the 1D-vertical model with input parameters $\tau^{a c 0}=0.03 \mathrm{~N} \mathrm{~m}^{-2}, \frac{\partial \eta}{\partial x}=0$ (excluding the land boundary effect), latitude $=30^{\circ} \mathrm{S}$, initial $\mathrm{MLD}=10 \mathrm{~m}$, initial stratification $=6^{\circ} \mathrm{C}$, water depth $=50 \mathrm{~m}$.

\section{Results}

\subsection{Diurnal-inertial resonance and mixing}

\subsubsection{Open ocean case}

We begin by considering a two layer system forced by a constant amplitude diurnal anticlockwise rotating wind stress at $30^{\circ} \mathrm{S}$, in the absence of a land boundary $(\partial \eta / \partial x=0)$. The amplitude of the applied wind stress is $0.03 \mathrm{~N} \mathrm{~m}^{-2}$, being typical of the amplitude of the diurnal anticlockwise rotary component of the wind stress $\left(\tau^{a c 0}\right)$ over St Helena Bay (Figure 9). Figure 3 shows the input forcing time-series for the model, the evolution of the resulting temperature and cross-shore velocity profiles, and the diapycnal mixing diagnostics 
described in Section 2.6. A diurnal anticlockwise rotating wind stress at $30^{\circ} \mathrm{S}$ represents the pure case of diurnal-inertial resonance, as the wind stress is always aligned with the surface inertial oscillation and so the energy flux from the wind to the ocean $\left(\overrightarrow{\tau_{s}} \cdot \overrightarrow{u_{s}}\right)$ is maximised. Stratification between the surface and subsurface layers restricts the generation of winddriven currents to within the surface mixed layer. In the absence of the land boundary effect subsurface currents are not generated. The impact of water depth is therefore negligible in this experiment. The enhancement of the surface inertial oscillation is accompanied by the deepening of the thermocline and the cooling of the surface waters due to the entrainment of sub-thermocline waters. The simulation indicates a steady enrichment of the surface layer with the subsurface tracer, as evidenced by the increase in $C_{s}$ over the simulation. The enhanced diapycnal mixing is driven by elevated bulk shear, which is shown to increase rapidly over the first few days of the simulation, peaking at day $\sim 5$, before decreasing thereafter.

Although the bulk shear production computed directly from the model is consistently higher than that predicted by the analytical theory of Burchard and Rippeth (2009) (Figure 3f), the results suggest that Equation 9 provides a useful lens through which to interpret the results. The initial increase in bulk shear is explained by the perfect alignment of the surface wind stress $\left(\overrightarrow{\tau_{s}}\right)$ with the surface current $\left(\overrightarrow{u_{s}}\right)$ and therefore the bulk shear vector $(\vec{S})$. The enhanced bulk shear drives an increase in interfacial mixing (represented by the last term in Equation 9) as well as an increased depth of the surface layer $\left(H_{s}\right)$, both of which serve to reduce shear production. The bottom shear stress term is negligible in this simulation due to the absence of a subsurface oscillation. Shear production lowers to zero when the interfacial mixing term balances the wind stress input term. In this way interfacial mixing represents a mechanism which limits the amplitude of the surface layer inertial oscillation.

It should be noted that simulations forced with a diurnal clockwise rotating wind stress at $30^{\circ} \mathrm{S}$ yield negligible current response as the winds continually dampen the rotating surface inertial oscillation, which by definition has an anticlockwise sense of rotation in the southern hemisphere. Figure S1 provides an example of such a case, and serves as a reference experiment for background levels of mixing in the absence of any notable current forcing. 

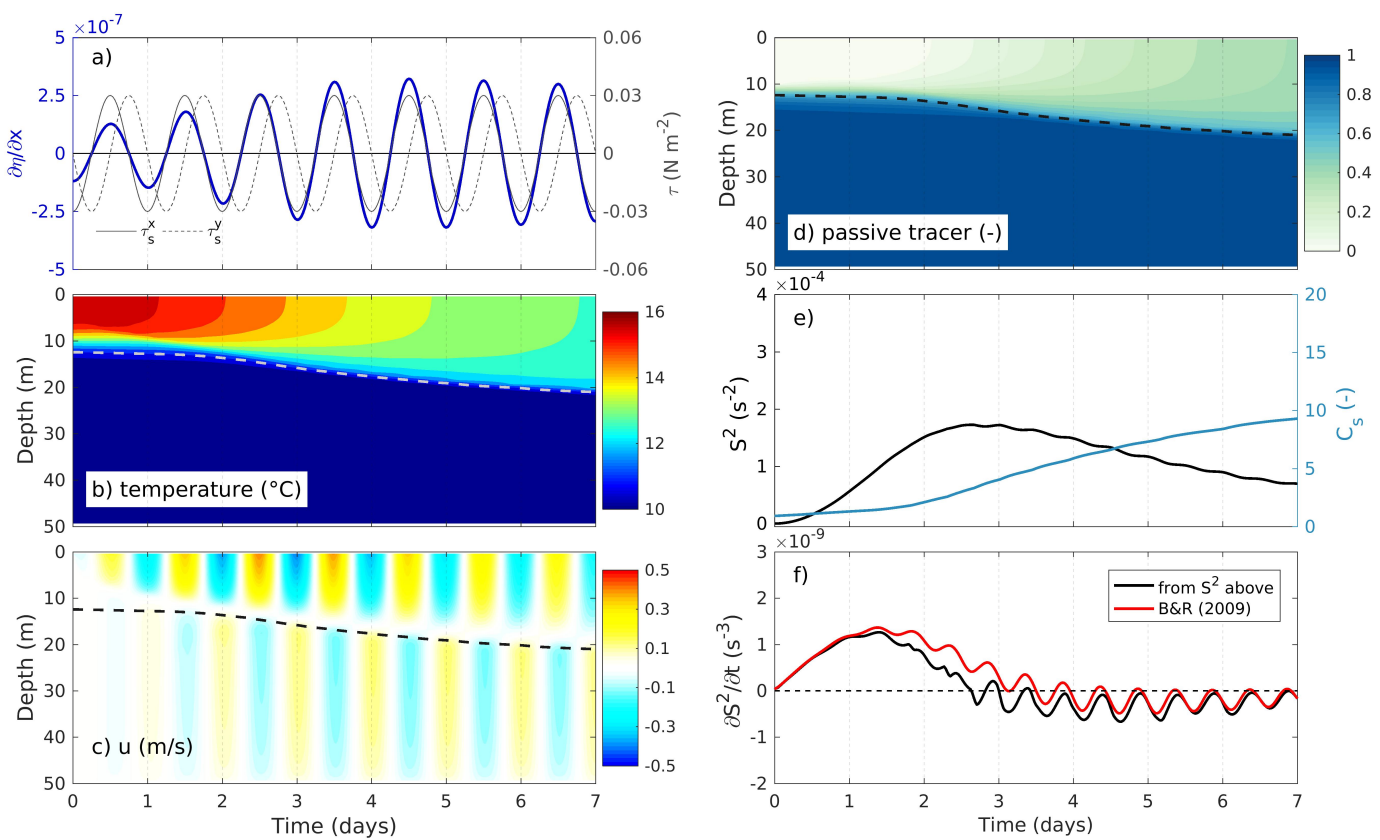

Figure 4. Effect of land boundary. Same as Figure 3 but with the 1D-vertical model now integrated including the 'Craig approximation' for coast-normal surface elevation gradient response (Equation 6).

\subsubsection{The land boundary effect}

Figure 4 builds on the model presented in Figure 3 by including the effect of the land boundary through the 'Craig approximation' for coast-normal surface elevation gradient response (Equation 6). For the considered case of pure diurnal-inertial resonance, $\frac{\partial \eta}{\partial x}$ is in phase with the cross-shore component of the wind stress $\left(\tau_{s}^{x}\right)$, generating a barotropic current response in the opposite direction to the surface inertial oscillation. The result is a significantly weakened surface inertial oscillation when compared to Figure 3, and the generation of a subsurface oscillation with a $180^{\circ}$ phase shift to the surface layer. At the start of the simulation, bottom friction is negligible and $\frac{\partial \eta}{\partial x}$ is determined from the wind stress terms of Equation 6 alone. As the subsurface oscillation increases in amplitude, so do bottom friction losses, serving to further enhance $\frac{\partial \eta}{\partial x}$ (as dictated by Equation 6), thereby dampening the surface oscillation. For the shown example, the bottom friction terms of Equation 6 approximately double the amplitude of $\frac{\partial \eta}{\partial x}$ before the solution stabilises.

A comparison of the mixing diagnostics from Figures 3 and 4 shows that forcing the model with the 'Craig approximation' serves to significantly reduce bulk shear and therefore 
diapycnal mixing. For the shown example, $C_{s}$ at 7 days is approximately halved through the inclusion of the land boundary effect. The evolution of bulk shear can again be interpreted using the bulk shear production theory of Burchard and Rippeth (2009). In addition to the processes already described for Figure 3, the subsurface oscillation generated by the 'Craig approximation' introduces a non-negligible bottom shear stress $\left(\overrightarrow{\tau_{b}}\right)$ which is at all times directly opposed to the surface shear stress $\left(\overrightarrow{\tau_{s}}\right)$. Equation 9 dictates that bulk shear production, and therefore diapycnal mixing, will be reduced as the cross-shore surface elevation gradient is enhanced.

It is important to note that the model solution results in near-zero depth averaged cross-shore transport, in line with the assumptions made in the formulation of the analytical theory for $\frac{\partial \eta}{\partial x}$ (Section 2.4). The bottom friction terms in Equation 6 are instrumental in this regard, as they account for bottom friction losses in the subsurface layer by amplifying $\frac{\partial \eta}{\partial x}$. In the absence of bottom friction terms in Equation 6, surface layer current velocities are over-estimated leading to a violation of the assumption of zero cross-shore transport, and the over-prediction of diapycnal mixing (Figure S2). Sensitivity tests indicate that bottom friction terms become negligible for maintaining near-zero cross-shore transport for water depths greater than $\sim 200 \mathrm{~m}$ (Figure S3).

\subsubsection{Effect of Ekman transport}

The results thus far have considered only a diurnally rotating wind stress of constant amplitude, representative of the land-sea breeze. Upwelling systems are however also defined by sustained alongshore wind stresses. Figure 5 builds on the model presented in Figure 4 by including the effect of a mean alongshore wind stress $\left(\bar{\tau}_{s}^{y}\right)$ of $0.1 \mathrm{~N} \mathrm{~m}^{-2}$, representative of a relatively strong alongshore wind stress over St Helena Bay (Figure 9). The classic case of Ekman transport in response to a constant $\tau_{s}^{y}$ of $0.1 \mathrm{~N} \mathrm{~m}^{-2}$ is provided in Figure S4. The inclusion of a mean alongshore wind stress is shown to introduce a mean surface transport in the offshore direction, consistent with Ekman theory, with the surface inertial oscillation superimposed onto the offshore transport (Figure 5c). The bulk shear time-series (Figure 5e) is characterised by a pronounced diurnal signal, or 'shear spikes' at the inertial frequency to use the terminology of Burchard and Rippeth (2009). The diurnal variability in bulk shear is superimposed onto a sub-inertial signal similar to that shown in Figure 4, namely that of an initial increase in shear followed by a subsequent decrease from day $\sim 3$ onwards. The sub-inertial variability in shear has been explained above, while the diurnal variability 

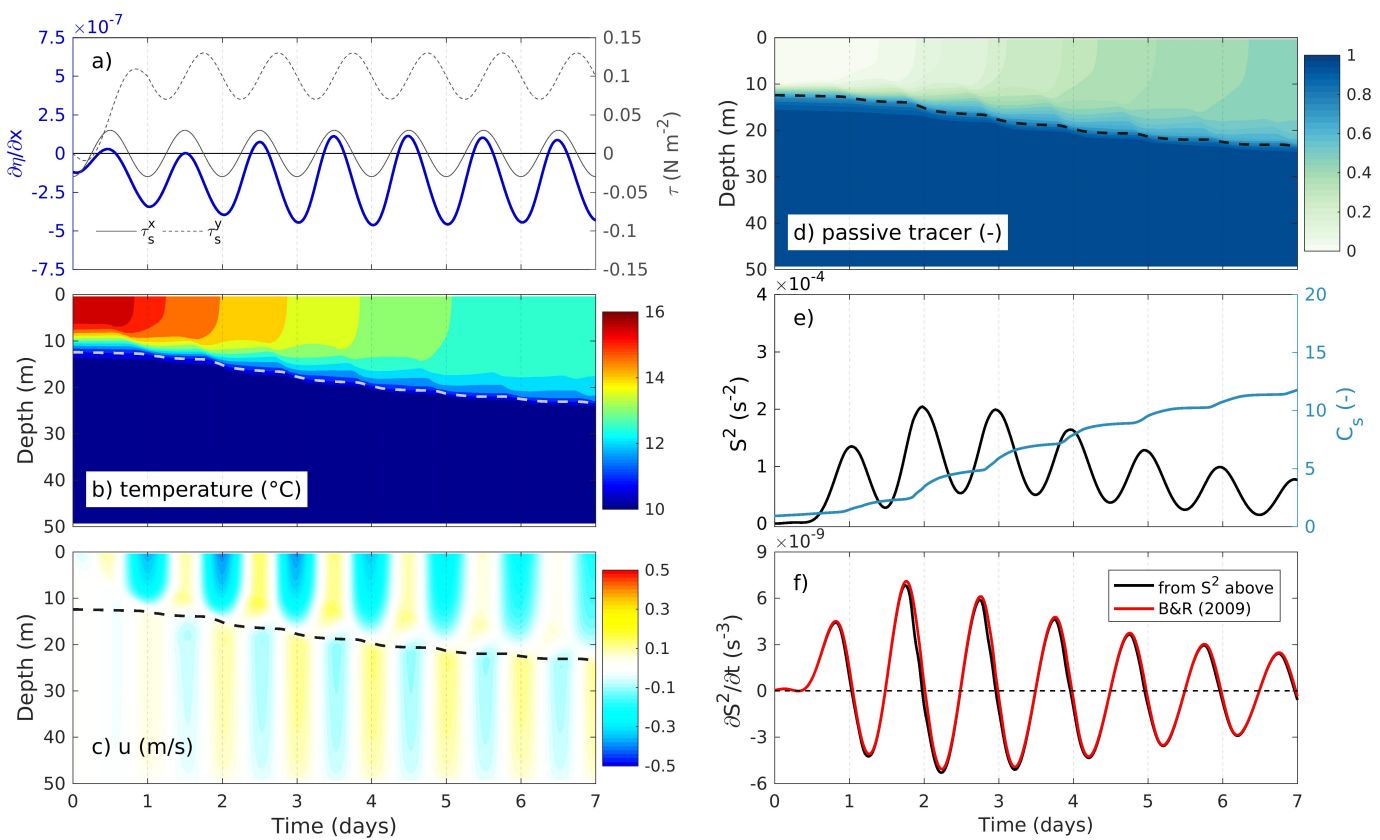

Figure 5. Effect of Ekman transport. Same as Figure 4, but with the 1D-vertical model now integrated including a mean alongshore wind stress $\left(\bar{\tau}_{s}^{y}\right)$ of $0.1 \mathrm{~N} \mathrm{~m}^{-2}$.

can again be interpreted using the bulk shear production theory of Burchard and Rippeth (2009). Bulk shear production (Figure 5f) is shown to be maximised when the $y$ component of the wind stress $\left(\tau_{s}^{y}\right)$ is highest, as at these times $\overrightarrow{\tau_{s}} \cdot \vec{S}$ is maximised. Shear production becomes negative at times when the surface current and wind stress are opposed. Bulk shear is maximised at a phase $\frac{\pi}{2}$ (6 hours) after the peak in bulk shear production, as this is when the surface inertial oscillation is aligned with the sub-inertial Ekman transport. The diurnal peaks in bulk shear are coincident with bursts of diapycnal mixing that inject the subsurface tracer into the surface layer. Although the impact on bulk shear and diapycnal mixing is significant at the diurnal time-scale, the net tracer injection into the surface layer $\left(C_{s}\right)$ is very similar to the simulation excluding the alongshore wind stress (Figure 4).

\subsection{Case study of St Helena Bay}

\subsubsection{Comparison with observations}

We now turn to the nearshore observations in St Helena Bay and assess the extent to which the simple 1D-vertical model dynamics described above can explain the observations. Figure 6 presents the evolution of observed and modelled temperature and velocity through 

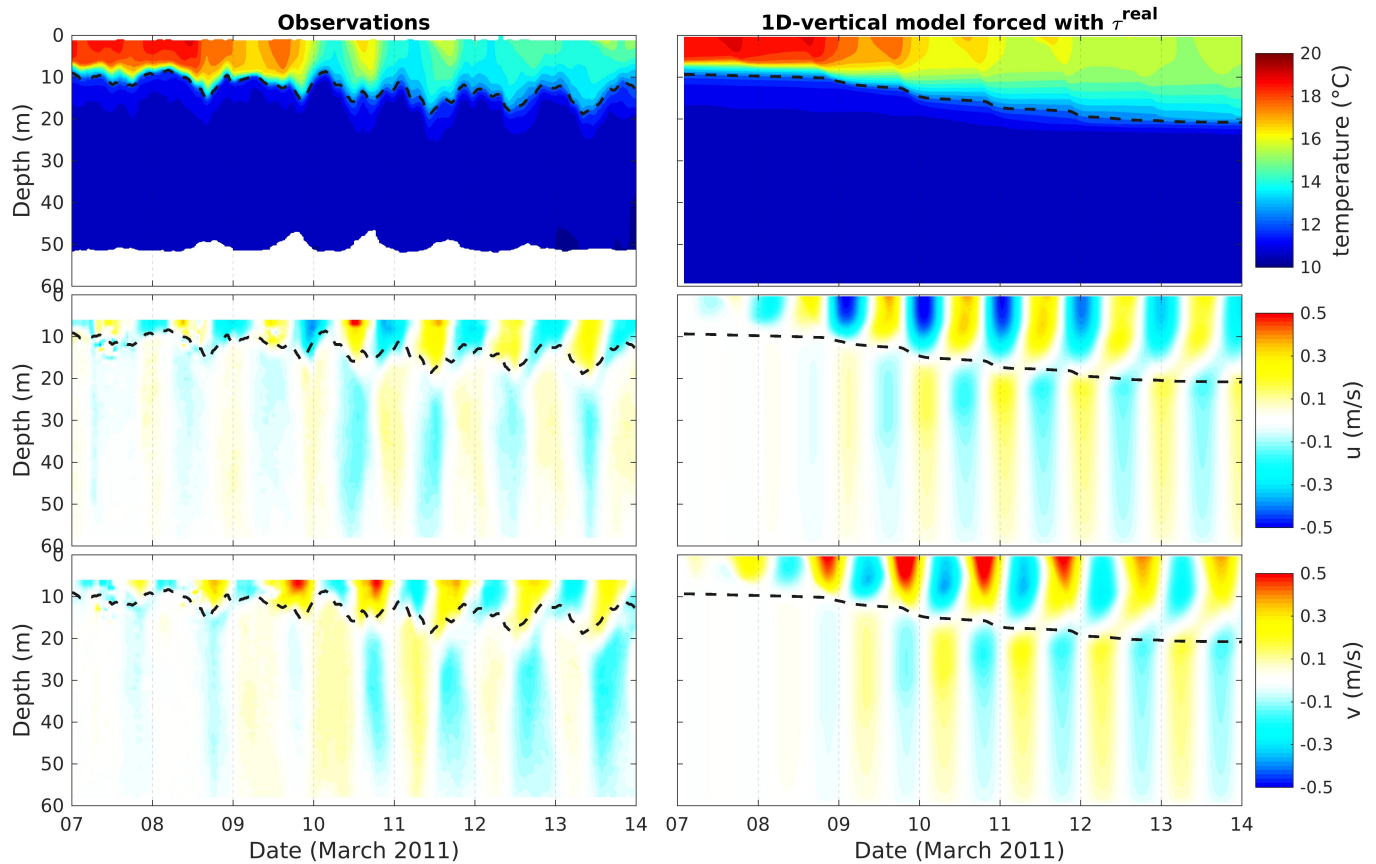

Figure 6. Observed (left) and modelled (right) temperature and velocity components over an upwelling event accompanied by diapycnal mixing in $\sim 60 \mathrm{~m}$ water depth in St Helena Bay ('WW' in Figure 1). The dotted line denotes the $12.5^{\circ} \mathrm{C}$ isotherm used as a proxy for the interface between the upper and lower layers.

the water column over the considered upwelling/mixing event. It is again noted that this event was specifically identified as a period where the observations clearly demonstrate the response of a highly stratified two layer system to the onset of upwelling favourable winds with an anticlockwise sense of rotation (Lucas et al., 2014). The temperature initial condition for the model was interpolated directly from the observations, while hourly wind stress and heat flux forcing for the model were derived from the CSAG WRF simulation at the location of the observations $\left(\tau^{\text {real }}\right.$ in Figure 2).

The model reproduces the observed two layer system comprised of anticlockwise oscillations at the diurnal-inertial frequency in both surface and subsurface layers with a $180^{\circ}$ phase shift between the two. The contamination of the surface ADCP data complicates a direct comparison of modelled and measured surface currents, however the amplitudes and phases are shown to be in surprisingly good agreement, considering the simplified physics of the model. The reasonable representation of subsurface velocities through the 'Craig approximation' provides some confidence in the methodology as applied in this paper. The 
good agreement may be surprising given that the 2D model experiments of Hyder et al. (2011) suggested that the 'Craig approximation' is not valid near the coast $(<140 \mathrm{~km})$ where non-linear terms cannot be ignored. Given that the observations are $\sim 12 \mathrm{~km}$ from the coast, significant deviations in surface elevation gradient from linear theory are expected at this location, however our results suggest that the net subsurface current response is predominantly driven by the linear physics of the theory. It is noted that the inclusion of the bottom friction terms in Equation 6 significantly improved the realism of the model, given the $\sim 60 \mathrm{~m}$ water depth of the observations.

Both the observations and the model indicate a rapid increase in surface current amplitude until 11 March, followed by a subsequent decrease. The onset of enhanced surface currents is accompanied by a deepening of the thermocline and a lowering of surface layer temperatures, consistent with the effects of diapycnal mixing. The model over-estimates the deepening of the thermocline, however the net cooling of the surface layer is somewhat contradictorily under-estimated. The observations reveal strong diurnal-inertial variability in surface temperature, particularly over the period 09-12 March, which is not reproduced in the model. The model does include a diurnal signal of surface layer warming due to the heat flux input, however the combination of mixing and heating alone cannot explain the observed diurnal variability. These discrepancies point to the presence of vertical and horizontal advection driven variability in the observations which is not included in the physics of the model. A further important difference between the model and the observations is that the observations include significant vertical displacements of the thermocline $(\sim 5 \mathrm{~m}$ amplitude) with a diurnal frequency which are absent in the model. This indicates the presence of near-inertial internal waves, likely generated by the convergence and divergence of the forced response near the land boundary, which are by definition not included in the physics of the model.

Figure 7 presents the evolution of bulk shear $\left(S^{2}\right)$ as derived from the data shown in Figure 6. The computation of $\overrightarrow{u_{s}}$ from the ADCP data required the filling of contaminated surface layers with data from the uppermost bin considered to contain good data. This is likely to result in an under-estimation of surface layer velocities (and therefore bulk shear) computed from the observations. The bulk shear vector computed from the measurements was low-pass filtered to remove frequencies higher than 12 hours. The progressive displacement plots show the surface layer currents to be comprised of inertial oscillations superimposed onto a background mean flow. The modelled mean flow is perpendicular to 

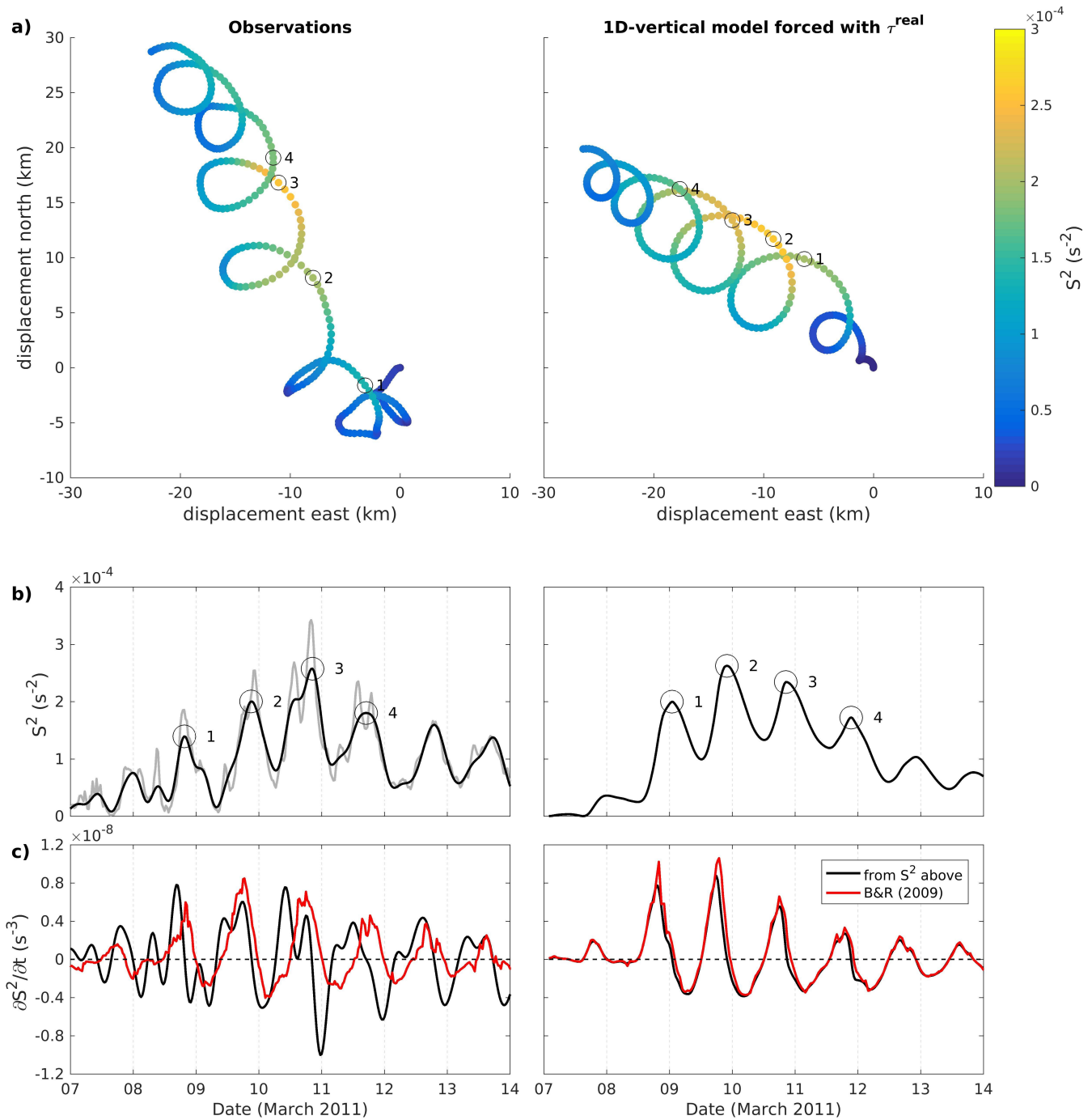

Figure 7. Observations (left) versus 1D-vertical model (right) during the event shown in Figure 6. (a) Progressive displacement plots derived from surface layer velocities $\left(\overrightarrow{u_{s}}\right)$. (b) Time-series of bulk shear $\left(S^{2}\right)$. The grey line shows the unfiltered bulk shear derived from the observations while the black line shows the low-pass filtered data. (c) Time-series of bulk shear production $\left(\frac{\partial S^{2}}{\partial t}\right)$ computed from the observations (left), model output (right), and the theory of Burchard and Rippeth (2009). 
the left of the major axis of the wind variability (Figure 2), consistent with Ekman transport. There is a difference in the orientation of the mean flow between the observations and the model, likely reflecting an error in the mean wind direction of the WRF model with respect to the actual winds over this event. Both the observations and the model show strong diurnal variability in bulk shear. The amplitude and timing of the 'shear spikes' in the model and the observations are in reasonable agreement. Four 'shear spikes' have been identified (labelled 1-4) and are indicated on the progressive displacement plots. In both the observations and the model, the 'shear spikes' are shown to occur when the oscillation and the mean flow are aligned leading to enhanced surface layer velocities and therefore bulk shear, consistent with the analytical configurations described in Section 3.1.3. The diurnal variability in bulk shear is superimposed onto a sub-inertial signal which indicates an increase in bulk shear until 10-11 March followed by a subsequent decrease, which is again consistent with the physics described for the analytical configurations. Comparison of the bulk shear production computed from the observations and the theory of Burchard and Rippeth (2009) (Figure 7c) reveals that the timing of the diurnal peaks is not always consistent. This could again be largely explained by errors in the WRF model wind direction over this event, as the theoretical bulk shear production is computed from the dot product of the WRF model wind stress and the observed bulk shear vector (Equation 9). The bulk shear production computed from the model is however in good agreement with the theory.

\subsection{2 $\tau^{a c 0}$ as a diagnostic for diapycnal mixing}

The comparison of the realistic model configuration with the observations shown above was carried out using realistic wind stresses $\left(\tau^{\text {real }}\right)$, while the analytical model configurations presented in Section 3.1 were carried out using a constant amplitude anticlockwise rotating wind stress $\left(\tau^{a c}\right)$. Figure 8 presents bulk shear and mixing results for simulations forced with both $\tau^{r e a l}$ and $\tau^{a c}$, to ascertain the extent to which $\tau^{a c}$ alone contributes to diapycnal mixing over the event. $\tau^{a c}$ for this simulation was computed from the 7 day period of 7-14 March 2011, as depicted by the red circle in Figure 2. Further detailed output from these simulations are provided in Figures S5 and S6. The notable difference between the simulations is the absence of diurnal 'shear spikes' in the simulation forced with $\tau^{a c}$ alone. In the absence of Ekman transport ( $\tau^{a c}$ has a mean wind stress of zero), the mechanism for the generation of diurnal 'shear spikes' through the superposition of the mean flow and the inertial oscillations is no longer present. The sub-inertial evolution of bulk shear is however 

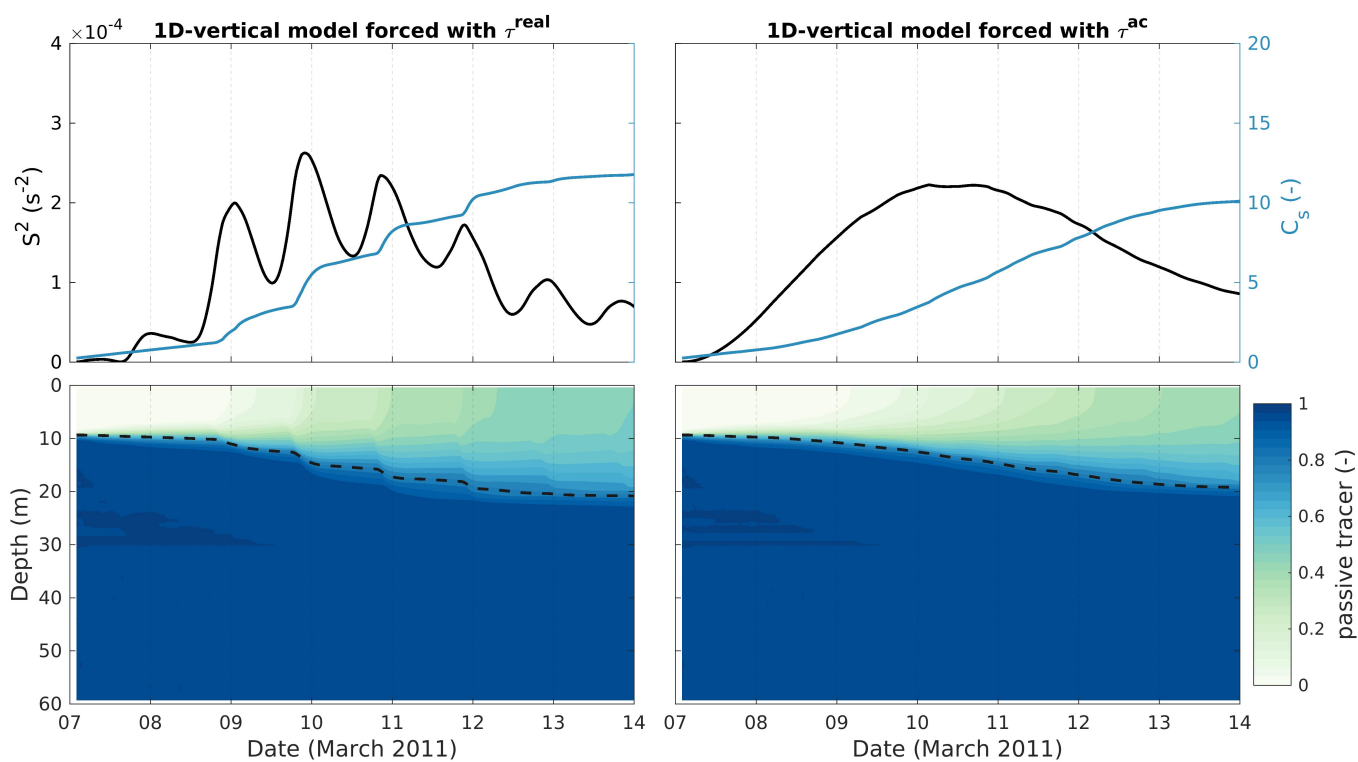

Figure 8. Bulk shear evolution and diapycnal mixing during the event shown in Figure 7 for simulations forced with realistic wind stresses $\tau^{\text {real }}$ (left) and its diurnal anticlockwise rotary component $\tau^{a c}$ (right). The wind stress forcing for these simulations is shown in Figure 2.

quite similar between the two simulations. Despite the large differences in the magnitude of the applied surface wind stresses $\left(\tau^{\text {real }}\right.$ attains a maximum value of $\sim 0.15 \mathrm{~N} \mathrm{~m}^{-2}$ while $\tau^{a c}$ has a constant amplitude of $0.03 \mathrm{~N} \mathrm{~m}^{-2}$ ), the cumulative diapycnal mixing response, as revealed by $C_{s}$, is comparable between the two simulations. The results therefore suggest that the amplitude of $\tau^{a c}\left(\tau^{a c 0}\right)$ can be used as a reasonable diagnostic for event-scale diapycnal mixing in response to the land-sea breeze. 'Shear spikes' introduced by the interaction of the surface inertial oscillation with the Ekman transport are shown to play a secondary role.

As $\tau^{a c 0}$ represents a diagnostic for diapycnal mixing, the spatial and seasonal variability of this parameter over St Helena Bay has been assessed, as shown in Figure 9. The monthly climatology of $\tau^{a c 0}$ computed at the location of the Lucas et al. (2014) observations (Figure 9a) reveals a distinct seasonality in the land-sea breeze, with a peak coinciding with the austral summer (November - January). This seasonality corresponds to that of the upwelling favourable winds in the region. Figure $9 \mathrm{c}$ reveals that $\tau^{a c 0}$ and $\tau_{s}^{y}$ are strongly correlated, indicating that periods of enhanced inertial oscillations are coincident with enhanced upwelling. The period coinciding with the historical mixing/upwelling event considered in this study (7-14 March 2011) is highlighted and shown to be typical in terms of both upwelling and land-sea breeze forcing. The spatial variability in $\tau^{a c 0}$ (Figure $9 \mathrm{~b}$ ) indicates a strong 

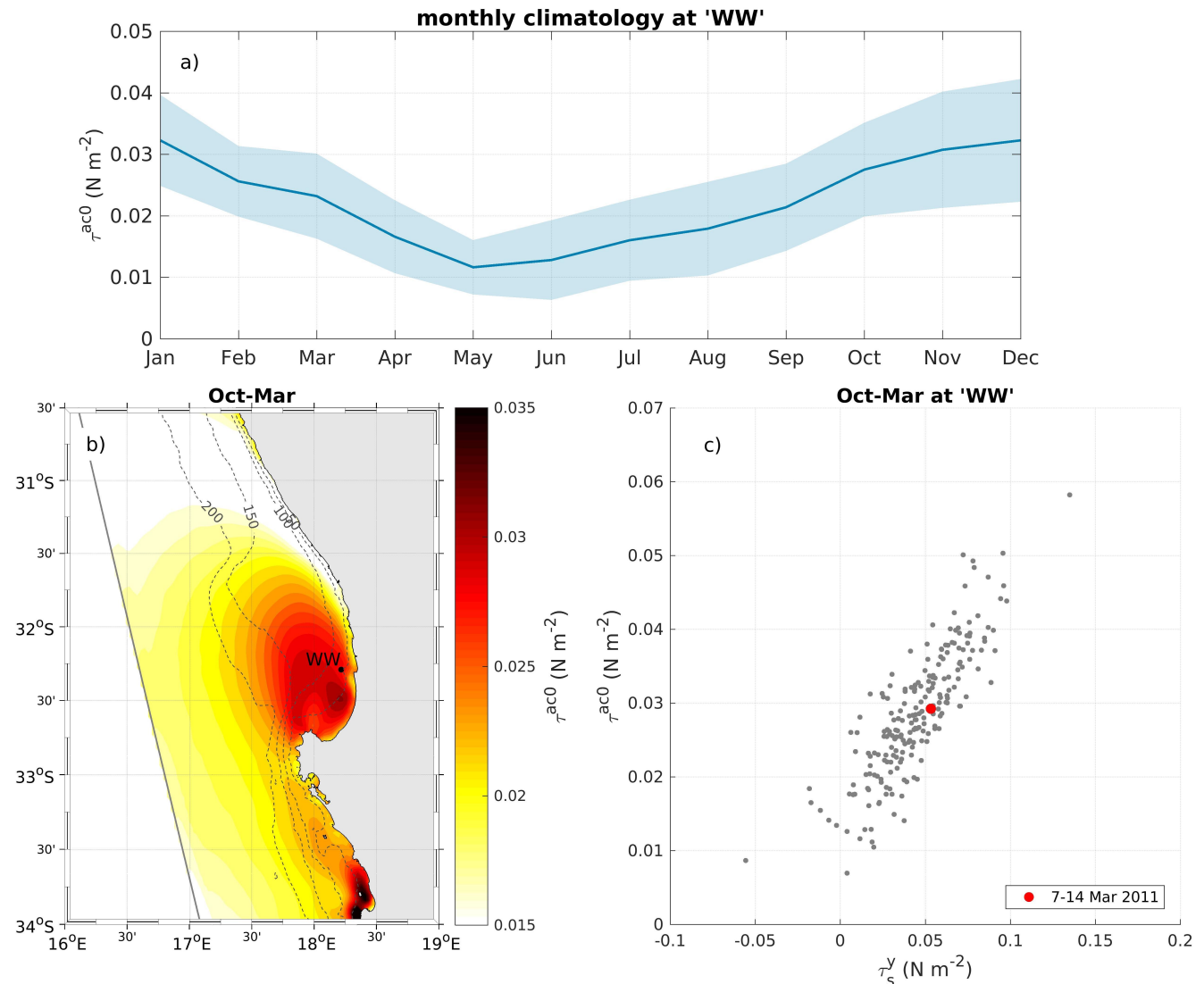

Figure 9. Spatial and seasonal variability in the amplitude of the diurnal anticlockwise rotary component of wind stress $\left(\tau^{a c 0}\right)$ over St Helena Bay. $\tau^{a c 0}$ has been estimated from consecutive 7 day windows over the 8 year duration of the $3 \mathrm{~km}$ resolution WRF simulation described in Section 2.2 . (a) Monthly climatology of $\tau^{a c 0} \pm 1 \sigma$ at the location of the Lucas et al. (2014) observations. (b) Spatial variability in the six month climatology of $\tau^{a c 0}$ over the upwelling favourable months of October to March. Overlain are the bathymetric contours. (c) Scatter plot of $\tau^{a c 0}$ vs the 7 day mean alongshore wind stress $\left(\tau_{s}^{y}\right)$ at the location of the Lucas et al. (2014) observations over the upwelling favourable months of October to March. 
amplification of the land-sea breeze over St Helena Bay. The orographic effects of Cape Columbine and high spatial variability in coastal sea surface temperatures in this region have been shown to significantly influence the spatial variability of low level winds (Burls \& Reason, 2008), and are likely to be responsible for the shown amplification.

\subsection{Sensitivity experiments}

Various sensitivity experiments have been carried out with the analytical model configuration in an attempt to generalise the results of the model (the 'Craig approximation' for the cross-shore free surface elevation gradient is included in these experiments). The baseline configuration employs the input parameters: latitude $=30^{\circ} \mathrm{S}$, initial $\mathrm{MLD}=10 \mathrm{~m}$, $\Delta T=6^{\circ} \mathrm{C}$ and water depth $=100 \mathrm{~m}$. Figure 10 presents the sensitivity of the model to varying each of these parameters, as quantified through the amplitude of the surface layer velocity $\left(\left|\overrightarrow{u_{s}}\right|\right)$ and the passive tracer integrated over the surface layer $\left(C_{s}\right)$, both averaged over the fifth day of each simulation. Results are presented for a range of amplitudes of diurnal anticlockwise rotating wind stress $\left(\tau^{a c 0}\right)$, being typical of those experienced over St Helena Bay (Figure 9).

Figure 10a indicates a strong dependence of both $\left|\overrightarrow{u_{s}}\right|$ and $C_{s}$ on latitude with the peak response at the critical latitude of $30^{\circ} \mathrm{S}$. The inertial response is shown to drop off within $6^{\circ}$ latitude either side of the critical latitude. The approximate latitude of St Helena Bay (SHB) is shown for reference, indicating that this site experiences near-peak response to diurnal forcing. For $\tau^{a c 0}=0.01 \mathrm{~N} \mathrm{~m}^{-2}$ the shear generated by the surface inertial oscillation is not high enough to trigger diapycnal mixing above background levels. Increasing $\tau^{a c 0}$ leads to an increase in $\left|\overrightarrow{u_{s}}\right|$ and $C_{s}$, however the amplitude of the surface oscillation is limited by enhanced diapycnal mixing, as dictated by bulk shear production theory used to interpret the results shown in Section 2.6.

The sensitivity of the model to initial MLD and stratification (Figure 10b and 10c) can be largely understood in terms of the gradient Richardson number, $R i=N^{2} / S^{2}$ which quantifies the balance of stabilising forces due to stratification $\left(N^{2}\right)$ and the destabilising forces due to vertically sheared flow $\left(S^{2}\right)$. Shallower surface mixed layers lead to higher amplitude surface currents and therefore enhanced shear. A given stratification can only sustain a defined shear before $R i$ is reduced sufficiently to trigger diapycnal mixing. Exaggerated mixing serves to dampen the amplitude of the surface oscillation as already described in 

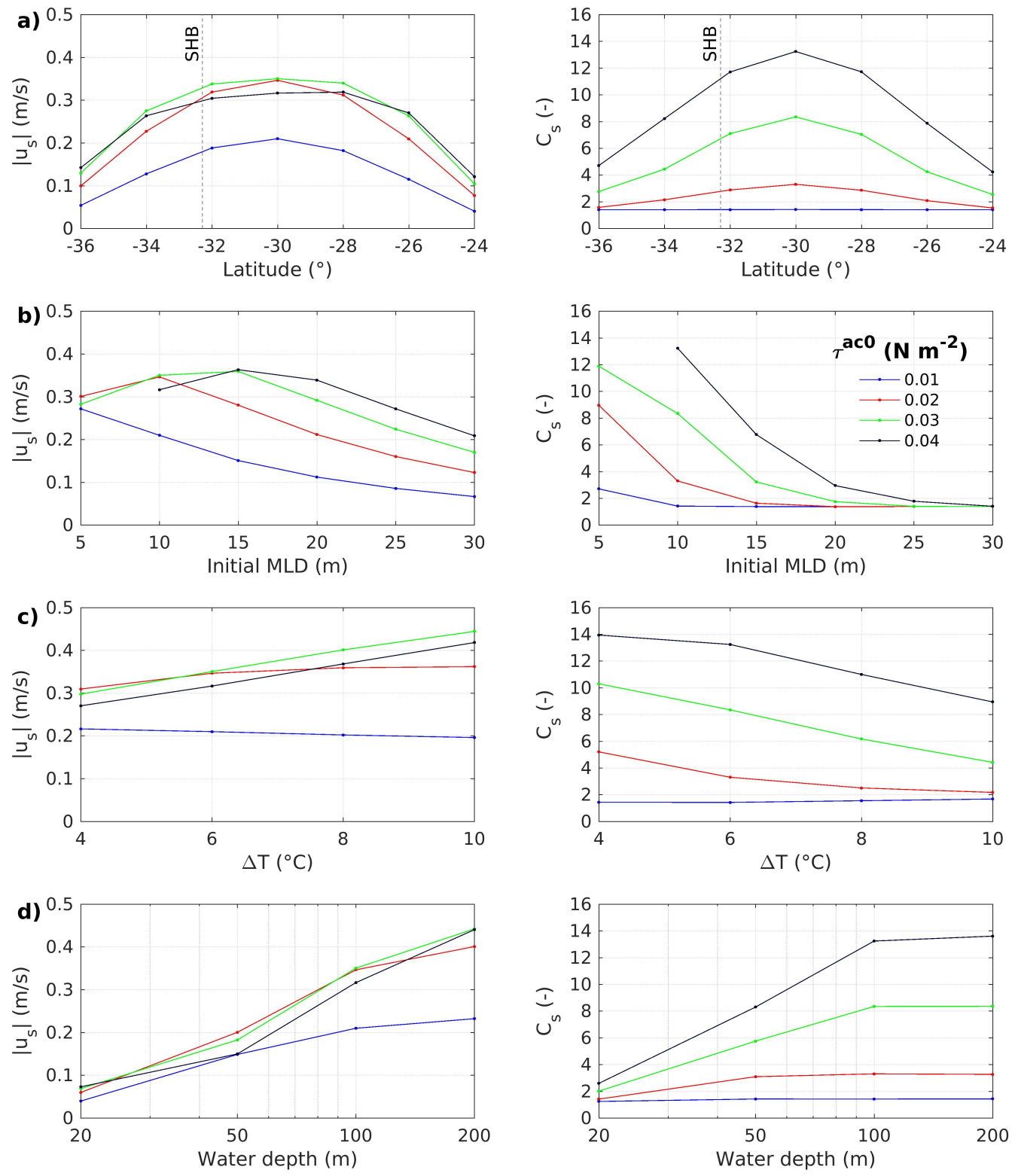

Figure 10. Sensitivity of the analytical model configuration, as quantified through the amplitude of the surface layer velocity $\left(\left|\overrightarrow{u_{s}}\right|\right)$ and the passive tracer integrated over the surface layer $\left(C_{s}\right)$, both averaged over the fifth day of each simulation. (a) Sensitivity to latitude. (b) Sensitivity to initial mixed layer depth (MLD). (c) Sensitivity to stratification ( $\Delta T$ represents the temperature difference between surface and subsurface layers). (d) Sensitivity to water depth. The different colour lines correspond to different wind stress amplitudes. 
Section 3.1.1. Diapycnal mixing is therefore particularly sensitive to initial MLD, while the surface current amplitude is modulated and even reduced in cases of exaggerated mixing. Note that the result for $\tau^{a c 0}=0.04 \mathrm{~N} \mathrm{~m}^{-2}$ and initial MLD $=5 \mathrm{~m}$ is not plotted as excessive mixing effectively eroded the two layer system to form a homogeneous water column with temperatures of between 10 and $11^{\circ} \mathrm{C}$. The results indicate that event-scale diapycnal mixing reduces to background levels for MLD's greater than $\sim 30 \mathrm{~m}$. Elevated stratification has a dampening effect on diapycnal mixing, while allowing for higher amplitude currents to be sustained in the surface layer. Surface current amplitude is however insensitive to stratification for low wind stress amplitudes which do not drive exaggerated mixing, as the depth of the surface layer remains largely unchanged over these simulations. The initial MLD therefore has a primary role in governing the diapycnal mixing response to diurnal-inertial resonance, while stratification plays a secondary modulating role.

Figure 10d shows that shallower water depths lead to significantly reduced surface current amplitudes and mixing. The formulation for the 'Craig approximation' (Equation 6) dictates that shallower water depths have an amplifying effect on $\frac{\partial \eta}{\partial x}$. As already described in Section 3.1, this has a dampening effect on both the amplitude of the surface layer oscillation as well as diapycnal mixing. Simulations run at $20 \mathrm{~m}$ water depth are shown to result in very low amplitude oscillations $\left(\left|\overrightarrow{u_{s}}\right|<0.1 \mathrm{~m} / \mathrm{s}\right.$ for all tested wind stress amplitudes), and a complete dampening of diapycnal mixing to near-background levels. The $C_{s}$ results from Figure $10 \mathrm{~d}$ at $100 \mathrm{~m}$ are very similar to those at $200 \mathrm{~m}$, indicating that the impact of the land boundary on diapycnal mixing from the locally generated inertial response becomes negligible for water depth for depths greater than $\sim 100 \mathrm{~m}$.

\section{Discussion and conclusions}

\subsection{Diapycnal mixing dynamics}

Despite the simplicity of the 1D-vertical model introduced in this paper, the results of the realistic configuration are in good agreement with nearshore observations over an upwelling event accompanied by diapycnal mixing in $\sim 60 \mathrm{~m}$ water depth in the Benguela system. One of the main limitations of applying 1D models to study diurnal-inertial resonance near a land boundary is the difficulty in reproducing the first baroclinic mode vertical structure of the currents (Zhang et al., 2010). Here we address this limitation through the implementation of the 'Craig approximation' for first order surface elevation gradient re- 
sponse, extending the formulation of Simpson et al. (2002) through the inclusion of bottom friction terms. The results of the model have been interpreted using the bulk shear production theory of Burchard and Rippeth (2009). This work represents the first application of this theory in the context of diurnal-inertial resonance near the critical latitude of $30^{\circ} \mathrm{N} / \mathrm{S}$. The theory dictates that bulk shear will be produced (and mixing enhanced) when the bulk shear vector is aligned with the surface and bottom shear stresses, weighted by the depth of the two layers, and moderated by interfacial mixing. Near latitudes of $30^{\circ} \mathrm{N} / \mathrm{S}$, the diurnal anticyclonic rotary component of the wind is always in alignment with the bulk shear vector induced by the presence of inertial oscillations, which provides a constant source of bulk shear production. The effect of the land boundary is to generate a subsurface oscillation with a $180^{\circ}$ phase shift with the surface layer, thereby introducing bottom shear stresses in the opposite direction to the surface stresses. The latter has a dampening effect on shear production (Figure 4), which in turn reduces diapycnal mixing. The land boundary effect becomes increasingly important for shallow water depths $(<\sim 100 \mathrm{~m})$, where bottom friction losses serve to amplify the response of the cross-shore surface elevation gradient, which in turn further dampens the amplitude of the surface inertial oscillations. For depths $<\sim 200 \mathrm{~m}$, the introduction of bottom friction terms in the formulation of the 'Craig approximation' is crucial for achieving realistic currents and mixing in the model through the maintenance of near-zero depth averaged cross-shore transport. Diapycnal mixing is reduced to near-background levels in water depths of $\sim 20 \mathrm{~m}$ (Figure 10d). In this way, the first order response of the cross-shore surface elevation gradient offers a mechanism for contributing to the well known decrease in near-inertial energy towards the coast (Shearman, 2005; C. Chen \& Xie, 1997; Xing et al., 2004).

Many previous studies cite the $180^{\circ}$ phase shift between surface and subsurface layers, introduced by the land boundary, as a source of shear and mixing. This is seemingly in contrast with our results which suggest that the land boundary has a dampening effect on diapycnal mixing associated with the forced response to the land-sea breeze. It is however important to emphasise that the 1D-vertical model excludes propagating near-inertial first baroclinic mode internal waves. These waves are known to be generated by the inertial pumping of the thermocline due to convergence and divergence of the forced response at the land boundary (Millot \& Crépon, 1981; Tintoré et al., 1995; S. Chen et al., 2017; Kelly, 2019). The large vertical displacements of the thermocline as seen in the observations (Figure 6) provide evidence for the propagating near-inertial internal wave component in the 
observations. First baroclinic mode internal waves also introduce a $180^{\circ}$ phase shift between surface and subsurface layers, which is an important contributor to diapycnal mixing (Xing et al., 2004; Zhang et al., 2010). Separating the contribution of the internal wave component from the locally forced response described in this paper is complicated by the similar vertical current structures and frequencies of these processes. The good agreement between observations and the 1D-vertical model however suggests that diapycnal mixing over the considered event was dominated by resonance between the local diurnal wind variability and the locally generated inertial oscillation, while the propagating near-inertial internal wave component was of lower importance. 2D numerical experiments designed to ascertain the diapycnal mixing contribution of near-inertial internal waves set up by diurnal-inertial resonance at a land boundary is a topic of ongoing investigation.

The introduction of a non-zero mean alongshore wind stress serves to introduce 'shear spikes' at the diurnal-inertial frequency, coinciding with times where the surface inertial oscillation and Ekman transport are aligned. While 'shear spikes' have been found to be important for driving diapycnal mixing and bloom enhancement in shallow stratified seas (Burchard \& Rippeth, 2009; Lincoln et al., 2016; Williams et al., 2013), our results suggest that this process plays a secondary role in the integrated nutrient enrichment of the surface layer, when compared with the diurnal-inertial resonance phenomenon (Figure 8). It should however be noted that the timing of the diurnal 'shear spikes' in relation to sunlight availability would have consequences for the diurnal variability in phytoplankton growth. Both observations and model results indicate night time nutrient enrichment of the surface layer over the considered event (Figure 7), which would benefit phytoplankton growth during the following day.

\subsection{Implications for St Helena Bay and EBUS generally}

St Helena Bay is exposed to a pronounced enhancement of the diurnal anticlockwise rotary component of the wind stress (Figure 9), which has been shown to be a reasonable diagnostic for event-scale diapycnal mixing (Figure 8). Sensitivity tests to latitude (Figure 10a) indicate that St Helena Bay $\left(\sim 32.5^{\circ} \mathrm{S}\right)$, experiences near-peak inertial response to diurnal forcing. These results alone provide strong evidence for the forcing mechanism of the energetic diurnal-inertial current variability which has been observed in the bay (Fawcett et al., 2008; Lucas et al., 2014). 
Productivity within St Helena Bay is largely understood in terms of the retentive properties of the bay which allow for the utilisation of upwelled nutrients during wind relaxation/reversal (G. Pitcher et al., 2010). As such, productivity tends to be highest in late summer when extended relaxation events following active upwelling allow for the formation of shallow stratified surface mixed layers, considered favourable for development of high biomass dinoflagellate blooms (Fawcett et al., 2007; G. C. Pitcher \& Weeks, 2006; G. Pitcher et al., 2010). Shallow surface mixed layers have also been shown to be a key determinant for enhanced diapycnal mixing, as moderated by the level of stratification between surface and subsurface layers (Figure 10b and 10c). Although relaxation events are generally associated with a lower amplitude land-sea breeze (Figure 9), even low amplitude diurnal wind variability would serve to moderate the formation of shallow mixed layers through the entrainment of subsurface waters and nutrients. Furthermore, successive events of enhanced diurnal wind variability would act on the inertial currents set up by the previous event, serving to further enhance the ocean response. The results presented in this paper therefore provide further evidence that the land-sea breeze plays a major role in determining the evolution of primary productivity within St Helena Bay through surface layer nutrient enrichment.

Given the significant impact of diurnal wind variability on the vertical water column structure, our results indicate that diapycnal mixing may have further implications for the nearshore sub-inertial upwelling/relaxation dynamics of St Helena Bay. Deeper surface mixed layers induced by nearshore mixing would reduce offshore surface Ekman velocities, thereby acting as a retention mechanism within the studied bay, and more generally in the EBUS regions. The modulation of cross-shore pressure gradients due to diapycnal mixing would also affect alongshore geostrophic currents and therefore bay-scale circulation. Observations in the Coastal Southern California Bight indicate that diurnal-inertial resonance can lead to steeper cross-shore isotherms and intensified alongshore flows (Nam \& Send, 2013). These processes are currently being investigated with a high resolution 3D model of St Helena Bay.

Although this work has used St Helena Bay as a case study, the results and implications are transferable to other regions, as all four major EBUS include land-sea breeze forcing near the critical latitude. A dedicated analyses of the diurnal anticlockwise rotary component of the wind stress could highlight other regions where the local inertial response and diapycnal mixing could be enhanced. A general consideration for future studies is the 
requirement for atmospheric products of sufficient spatial and temporal resolution to capture the nearshore spatial variability in the land-sea breeze. This can be considerable where local orographic features and sea surface temperatures may significantly impact nearshore diurnal wind variability, as highlighted by Figure 9 . The inability to resolve the nearshore features of the land-sea breeze may be a significant shortcoming in large scale models which aim at simulating productivity in coastal upwelling systems. This study suggests that the mostly affected regions would be those where the development of shallow surface mixed layers through retention coincide with the local amplification of the land-sea breeze.

\section{Appendix A GLS implementation in CROCO}

The objective of this section is to describe the current implementation of a Generic Length Scale (GLS) turbulence scheme in CROCO to determine $K_{m}$ and $K_{s}$ in (1). First of all, as usually done in most implementations, the assumption of a horizontally homogeneous flow is made and vertical advection is neglected. Following Umlauf and Burchard (2003), the equations satisfied by the two prognostic variables $e$ (the kinetic energy) and $\psi$ (the generic length scale) are:

$$
\begin{array}{rlrl}
\frac{\partial e}{\partial t} & =\frac{\partial}{\partial z}\left(K_{e} \frac{\partial e}{\partial z}\right)+P+B-\varepsilon, & K_{e} & =K_{m} / \mathrm{Sc}_{e} \\
\frac{\partial \psi}{\partial t} & =\frac{\partial}{\partial z}\left(K_{\psi} \frac{\partial \psi}{\partial z}\right)+\psi e^{-1}\left(\beta_{1} P+\beta_{3}^{ \pm} B-\beta_{2} \varepsilon\right), & K_{\psi}=K_{m} / \mathrm{Sc}_{\psi}
\end{array}
$$

where the $\beta_{j}(\mathrm{j}=1,3)$ are constants to be defined, $P$ represents the turbulent kinetic energy (TKE) production by vertical shear $P=K_{m}\left[\left(\frac{\partial u}{\partial z}\right)^{2}+\left(\frac{\partial v}{\partial z}\right)^{2}\right]$ and $B$ the TKE destruction by stratification $B=-K_{s} N^{2}$ (with $N^{2}$ the local Brunt-Väisälä frequency). The dissipation rate $\varepsilon$ is related to the generic length scale $\psi$ following:

$$
\varepsilon=\left(c_{\mu}^{0}\right)^{3+p / n} e^{3 / 2+m / n} \psi^{-1 / n}, \quad \psi=\left(c_{\mu}^{0}\right)^{p} e^{m} l^{n}, \quad l=\left(c_{\mu}^{0}\right)^{3} e^{3 / 2} \varepsilon^{-1},
$$

with $l$ a mixing length and $c_{\mu}^{0}$ a constant (whose value is between 0.526 and 0.555 ) to be defined. Depending on the parameter values for the triplet $(m, n, p)$ the GLS scheme will either correspond to a $k-\varepsilon$, a $k-\omega$ or the so-called generic (Umlauf \& Burchard, 2003) turbulence scheme (the so-called $k-k l$ scheme is not implemented in CROCO to simplify the code and because this scheme does not generally outperform other schemes).

Once the quantities $e$ and $\psi$ (hence $\varepsilon$ ) are known, the turbulent viscosity/diffusivity are given by:

$$
K_{m}=c_{\mu}\left(\frac{e^{2}}{\varepsilon}\right)=\frac{c_{\mu}}{\left(c_{\mu}^{0}\right)^{3}}(l \sqrt{e}), \quad K_{s}=c_{\mu}^{\prime}\left(\frac{e^{2}}{\varepsilon}\right)=\frac{c_{\mu}^{\prime}}{\left(c_{\mu}^{0}\right)^{3}}(l \sqrt{e}),
$$


Table A1. Parameter values corresponding to each particular GLS model.

\begin{tabular}{cccccccccc}
\hline GLS model & $m$ & $n$ & $p$ & $\beta_{1}$ & $\beta_{2}$ & $\beta_{3}^{-}$ & $\beta_{3}^{+}$ & $\mathrm{Sc}_{e}$ & $\mathrm{Sc}_{\psi}$ \\
\hline$k-\omega$ & 0.5 & -1 & -1 & 0.555 & 0.833 & -0.6 & 1 & 0.5 & 0.5 \\
$k-\varepsilon$ & 1.5 & -1 & 3 & 1.44 & 1.92 & -0.4 & 1 & 1 & 0.7692 \\
Gen & 1 & -0.67 & 2 & 1 & 1.22 & 0.05 & 1 & 1.25 & 0.9345 \\
\hline
\end{tabular}

where $c_{\mu}$ and $c_{\mu}^{\prime}$ are determined through so-called stability functions (see below).

\section{Choice of parameter values and stability functions}

A particular GLS occurence is defined by the following parameters :

- The exponents $(m, n, p)$ in the definition of $\varepsilon$

- The Schmidt numbers $\mathrm{Sc}_{e}$ and $\mathrm{Sc}_{\psi}$

- The coefficients $\beta_{j}(\mathrm{j}=1,3)$

- The constant $c_{\mu}^{0}$

- The stability functions which are generally function of:

$$
\alpha_{M}=\left(\frac{e}{\varepsilon}\right)^{2}\left[\left(\frac{\partial u}{\partial z}\right)^{2}+\left(\frac{\partial v}{\partial z}\right)^{2}\right], \quad \alpha_{N}=\left(\frac{e}{\varepsilon}\right)^{2} N^{2}
$$

where $(m, n, p), \mathrm{Sc}_{e}, \mathrm{Sc}_{\psi}, \beta_{j}(j=1,3)$ are tied to a particular choice of GLS scheme (see Table A1) while $c_{\mu}^{0}, c_{\mu}$ and $c_{\mu}^{\prime}$ are tied to a particular choice of stability function. The formulation of numerous stability functions can be reconciled when written using the generic form:

$$
\begin{aligned}
c_{\mu} & =\frac{n_{0}+n_{1} \alpha_{N}+n_{2} \alpha_{M}}{d_{0}+d_{1} \alpha_{N}+d_{2} \alpha_{M}+d_{3} \alpha_{N} \alpha_{M}+d_{4} \alpha_{N}^{2}+d_{5} \alpha_{M}^{2}}, \\
c_{\mu}^{\prime} & =\frac{n_{0}^{\prime}+n_{1}^{\prime} \alpha_{N}+n_{2}^{\prime} \alpha_{M}}{d_{0}+d_{1} \alpha_{N}+d_{2} \alpha_{M}+d_{3} \alpha_{N} \alpha_{M}+d_{4} \alpha_{N}^{2}+d_{5} \alpha_{M}^{2}},
\end{aligned}
$$

where a given choice of stability function will define the parameter values for $n_{i}, d_{j}$, and $n_{k}^{\prime}$. For the present study the so-called CANUTO-A stability function is used.

The quantities $\alpha_{N}$ and $\alpha_{M}$ in the formulation of $c_{\mu}$ and $c_{\mu}^{\prime}$ must satisfy some constraints to guarantee the regularity of numerical solutions. In CROCO, the following steps are done: 
1. Apply the Galperin (1988) limitation i.e. $l \leq l_{\text {lim }}=\beta_{\text {galp }} \sqrt{2 e / N^{2}}$ on $\psi$ with $\beta_{\text {galp }}=$ 0.53. The first step is to use this mixing length $l_{\text {lim }}$ to compute $\psi_{\min }=\left(c_{\mu}^{0}\right)^{p} e^{m}\left(l_{\lim }\right)^{n}$ and to correct $\psi$ to satisfy the constraint $\psi=\max \left(\psi, \psi_{\min }\right)$ here the max function is used since the exponent $n$ is negative whatever the GLS scheme.

2. Compute the dissipation rate $\varepsilon=\left(c_{\mu}^{0}\right)^{3+p / n} e^{3 / 2+m / n} \psi^{-1 / n}$ and correct it $\varepsilon=\max \left(\varepsilon, \varepsilon_{\min }\right)$

3. Compute $\alpha_{N}$ and $\alpha_{M}$ using (A5), and apply "stability and realisability" constraints following Umlauf and Burchard (2003) (Sec. 4). A first constraint applies on $\alpha_{N}$ to ensure that $-\partial_{\alpha_{N}}\left(c_{\mu}^{\prime} / \alpha_{N}\right)>0$ to prevent the occurence of oscillations in $c_{\mu}^{\prime}$. This translates into the following limiter:

$\alpha_{N}^{\min }=\frac{-\left(d_{1}+n_{0}^{\prime}\right)+\sqrt{\left(d_{1}+n_{0}^{\prime}\right)^{2}-4 d_{0}\left(d_{4}+n_{1}^{\prime}\right)}}{2\left(d_{4}+n_{1}^{\prime}\right)}, \quad \alpha_{N}=\min \left(\max \left(0.73 \alpha_{N}^{\min }\right), 10^{10}\right)$,

where the coefficient 0.73 is used to ensure the so-called realisability and has been empirically computed thanks to Table 3 in Umlauf and Burchard (2003) in order to satisfy their constraint (48). Then an upper limit is applied on $\alpha_{M}$ to ensure that $\partial_{\alpha_{M}}\left(c_{\mu} \sqrt{\alpha_{M}}\right) \geq 0$ which is also a prerequisite for stability reasons: $\alpha_{M}^{\max }=\frac{d_{0} n_{0}+\left(d_{0} n_{1}+d_{1} n_{0}\right) \alpha_{N}+\left(d_{1} n_{1}+d_{4} n_{0}\right) \alpha_{N}^{2}+d_{4} n_{1} \alpha_{N}^{3}}{d_{2} n_{0}+\left(d_{2} n_{1}+d_{3} n_{0}\right) \alpha_{N}+\left(d_{3} n_{1}\right) \alpha_{N}^{2}}, \quad \alpha_{M}=\min \left(\alpha_{M}, \alpha_{M}^{\max }\right)$.

Once those quantities are computed, stability functions are evaluated as well as the turbulent viscosity/diffusivity.

\section{Surface and bottom boundary conditions}

In the current version of CROCO, both $e$ and $\psi$ are formulated with Neumann boundary conditions at the top and at the bottom. However the nature of those boundary conditions also requires the determination of bottom and surface values for $e$ and $\psi$.

- For turbulent kinetic energy, the "diagnostic" surface and bottom values are given by:

$$
e_{\mathrm{sfc}}=\left(u_{\star}^{s} / c_{\mu}^{0}\right)^{2}, \quad e_{\mathrm{bot}}=\left(u_{\star}^{b} / c_{\mu}^{0}\right)^{2},
$$

and simple homogeneous Neumann boundary conditions are applied:

$$
\left.K_{e} \frac{\partial}{\partial z} e\right|_{\mathrm{sfc}}=0,\left.\quad K_{e} \frac{\partial}{\partial z} e\right|_{\text {bot }}=0 .
$$

In practice, due to the placement of $e$ and $\psi$ on the computational grid, the Neumann boundary condition is not applied strictly at the surface (resp. at the bottom) but at 
$z=z_{N}$ (resp. $z=z_{1}$ ) whereas the surface (resp. bottom) is located at $z=z_{N+1 / 2}$ (resp. $z=z_{1 / 2}$ ) with $N$ the number of vertical levels (i.e. the number of cells in the vertical).

- For the generic length scale, a roughness is defined as:

$$
z_{0, s}=\max \left\{10^{-2} \mathrm{~m}, \frac{C_{\mathrm{ch}}}{g}\left(u_{\star}^{s}\right)^{2}\right\}, \quad C_{\mathrm{ch}}=1400,
$$

at the surface and:

$$
z_{0, b}=\max \left\{10^{-4} \mathrm{~m}, \mathrm{Zob}\right\},
$$

at the bottom with Zob a user defined roughness length. Again, the boundary conditions are applied at the center of the shallowest and deepest grid cells and not at their interfaces which means that the relevant length scales are:

$$
L_{\mathrm{sfc}}=\kappa\left(\frac{\Delta z_{N}}{2}+z_{0, s}\right), \quad L_{\mathrm{bot}}=\kappa\left(\frac{\Delta z_{1}}{2}+z_{0, b}\right),
$$

with $\kappa$ the von Kármán constant. Moreover TKE values are interpolated at $z=z_{N}$ and $z=z_{1}$ :

$$
\widetilde{e}_{\mathrm{sfc}}=\frac{1}{2}\left(e_{\mathrm{sfc}}+e_{\mathrm{N}-1 / 2}\right), \quad \widetilde{e}_{\mathrm{bot}}=\frac{1}{2}\left(e_{\mathrm{bot}}+e_{3 / 2}\right),
$$

where $e_{\mathrm{sfc}}$ and $e_{\mathrm{bot}}$ are the diagnostic values given above. The "diagnostic" surface and bottom values for $\psi$ are thus given by:

$$
\psi_{\text {sfc }}=\left(c_{\mu}^{0}\right)^{p}\left(L_{\mathrm{sfc}}\right)^{n}\left(\widetilde{e}_{\mathrm{sfc}}\right)^{m}, \quad \psi_{\mathrm{bot}}=\left(c_{\mu}^{0}\right)^{p}\left(L_{\mathrm{bot}}\right)^{n}\left(\widetilde{e}_{\mathrm{bot}}\right)^{m} .
$$

The surface and bottom fluxes are then defined as:

$$
\begin{gathered}
\mathcal{F}_{\psi}^{\mathrm{sfc}}=\left.K_{\psi} \partial_{z} \psi\right|_{\mathrm{sfc}}=-n\left(c_{\mu}^{0}\right)^{p+1} \frac{\kappa}{\mathrm{Sc}_{\psi}}\left(\widetilde{\mathrm{e}}_{\mathrm{sfc}}\right)^{m+1 / 2}\left(L_{\mathrm{sfc}}\right)^{n}, \\
\mathcal{F}_{\psi}^{\text {bot }}=\left.K_{\psi} \partial_{z} \psi\right|_{\mathrm{bot}}=-n\left(c_{\mu}^{0}\right)^{p+1} \frac{\kappa}{\mathrm{Sc}_{\psi}}\left(\widetilde{e}_{\mathrm{bot}}\right)^{m+1 / 2}\left(L_{\mathrm{bot}}\right)^{n},
\end{gathered}
$$

which correspond to the Neumann boundary conditions applied in the code.

\section{Acknowledgments}

The financial assistance of the South African Environmental Observation Network (SAEON) towards this research is acknowledged. Opinions expressed and conclusions arrived at are those of the author(s) and are not necessarily to be attributed to SEAON. Giles Fearon further acknowledges grants from LabexMER and the French Embassy in South Africa 
which greatly facilitated this research. We thank the Climate Systems Analysis Group (CSAG) for the provision of their WRF atmospheric model output and the South African Navy Hydrographic Office (SANHO) for the provision of bathymetric data. The study benefitted from computational facilities provided by the University of Cape Town's ICTS High Performance Computing team: hpc.uct.ac.za.

\section{References}

Aguiar-González, B., Rodríguez-Santana, Á., Cisneros-Aguirre, J., \& Martínez-Marrero, A. (2011, August). Diurnal-inertial motions and diapycnal mixing on the Portuguese shelf. Continental Shelf Research, 31(11), 1193-1201. doi: 10.1016/j.csr.2011.04.015

Alford, M. H. (2001, August). Internal Swell Generation: The Spatial Distribution of Energy Flux from the Wind to Mixed Layer Near-Inertial Motions. Journal of Physical Oceanography, 31(8), 2359-2368. doi: 10.1175/1520-0485(2001)031〈2359:ISGTSD $\rangle 2$ $.0 . \mathrm{CO} ; 2$

Alford, M. H., MacKinnon, J. A., Simmons, H. L., \& Nash, J. D. (2016, January). NearInertial Internal Gravity Waves in the Ocean. Annual Review of Marine Science, 8(1), 95-123. doi: 10.1146/annurev-marine-010814-015746

Burchard, H., \& Rippeth, T. P. (2009, April). Generation of Bulk Shear Spikes in Shallow Stratified Tidal Seas. Journal of Physical Oceanography, 39(4), 969-985. doi: 10.1175/ 2008JPO4074.1

Burls, N., \& Reason, C. (2008, November). Modelling the sensitivity of coastal winds over the Southern Benguela upwelling system to different SST forcing. Journal of Marine Systems, 74(1-2), 561-584. doi: 10.1016/j.jmarsys.2008.04.009

Chen, C., \& Xie, L. (1997). A numerical study of wind-induced, near-inertial oscillations over the Texas-Louisiana shelf. Journal of Geophysical Research: Oceans, 102(C7), 15583-15593. doi: 10.1029/97JC00228

Chen, S., Chen, D., \& Xing, J. (2017, October). A study on some basic features of inertial oscillations and near-inertial internal waves. Ocean Science, 13(5), 829-836. doi: 10.5194/os-13-829-2017

Craig, P. D. (1989, November). A model of diurnally forced vertical current structure near $30^{\circ}$ latitude. Continental Shelf Research, 9(11), 965-980. doi: 10.1016/0278-4343(89) $90002-2$

D'Asaro, E. A. (1985, August). The Energy Flux from the Wind to Near-Inertial Motions 
in the Surface Mixed Layer. Journal of Physical Oceanography, 15(8), 1043-1059. doi: 10.1175/1520-0485(1985)015〈1043:TEFFTW $\rangle 2.0 . C O ; 2$

Demarcq, H., Barlow, R., \& Hutchings, L. (2007, August). Application of a chlorophyll index derived from satellite data to investigate the variability of phytoplankton in the Benguela ecosystem. African Journal of Marine Science, 29(2), 271-282. doi: 10.2989/AJMS.2007.29.2.11.194

Ekman, V. W. (1905). On the influence of the earth's rotation on ocean currents. Arkiv för Matematik, Astronomi och Fysik, 2(11), 1-53.

Fawcett, A., Pitcher, G., Bernard, S., Cembella, A., \& Kudela, R. (2007, October). Contrasting wind patterns and toxigenic phytoplankton in the southern Benguela upwelling system. Marine Ecology Progress Series, 348, 19-31. doi: 10.3354/meps07027

Fawcett, A., Pitcher, G., \& Shillington, F. (2008, May). Nearshore currents on the southern Namaqua shelf of the Benguela upwelling system. Continental Shelf Research, 28(8), 1026-1039. doi: $10.1016 /$ j.csr.2008.02.005

Gille, S. T. (2003). Measuring the sea breeze from QuikSCAT Scatterometry. Geophysical Research Letters, 30(3). doi: 10.1029/2002GL016230

Gille, S. T. (2005). Global observations of the land breeze. Geophysical Research Letters, 32(5). doi: 10.1029/2004GL022139

Hyder, P., Simpson, J., Xing, J., \& Gille, S. (2011, October). Observations over an annual cycle and simulations of wind-forced oscillations near the critical latitude for diurnal-inertial resonance. Continental Shelf Research, 31(15), 1576-1591. doi: 10.1016/j.csr.2011.06.001

Jackett, D. R., \& Mcdougall, T. J. (1995, April). Minimal Adjustment of Hydrographic Profiles to Achieve Static Stability. Journal of Atmospheric and Oceanic Technology, 12(2), 381-389. doi: 10.1175/1520-0426(1995)012〈0381:MAOHPT $\rangle 2.0 . C O ; 2$

Jarosz, E., Hallock, Z., \& Teague, W. (2007, November). Near-inertial currents in the DeSoto Canyon region. Continental Shelf Research, 27(19), 2407-2426. doi: 10.1016/ j.csr.2007.06.014

Kelly, S. M. (2019, November). Coastally Generated Near-Inertial Waves. Journal of Physical Oceanography, 49(11), 2979-2995. doi: 10.1175/JPO-D-18-0148.1

Large, W. G., \& Pond, S. (1981, March). Open Ocean Momentum Flux Measurements in Moderate to Strong Winds. Journal of Physical Oceanography, 11(3), 324-336. doi: 10.1175/1520-0485(1981)011〈0324:OOMFMI $\rangle 2.0 . C O ; 2$ 
Lennard, C., Hahmann, A. N., Badger, J., Mortensen, N. G., \& Argent, B. (2015, August). Development of a Numerical Wind Atlas for South Africa. Energy Procedia, 76, 128137. doi: $10.1016 /$ j.egypro.2015.07.873

Lincoln, B. J., Rippeth, T. P., \& Simpson, J. H. (2016, August). Surface mixed layer deepening through wind shear alignment in a seasonally stratified shallow sea: Winddriven mixed layer deepening. Journal of Geophysical Research: Oceans, 121(8), 6021-6034. doi: 10.1002/2015JC011382

Lucas, A. J., Pitcher, G. C., Probyn, T. A., \& Kudela, R. M. (2014, March). The influence of diurnal winds on phytoplankton dynamics in a coastal upwelling system off southwestern Africa. Deep Sea Research Part II: Topical Studies in Oceanography, 101, 50-62. doi: $10.1016 /$ j.dsr2.2013.01.016

Millot, C., \& Crépon, M. (1981). Inertial Oscillations on the Continentral Shelf aof the Gulf of Lions - Observations and Theory. Journal of Physical Oceanography, 11, 639-657.

Nam, S., \& Send, U. (2013, March). Resonant Diurnal Oscillations and Mean Alongshore Flows Driven by Sea/Land Breeze Forcing in the Coastal Southern California Bight. Journal of Physical Oceanography, 43(3), 616-630. doi: 10.1175/JPO-D-11-0148.1

Pauly, D., \& Christensen, V. (1995). Primary production required to sustain global fisheries. Nature, $374,4$.

Pettigrew, N. R. (1980). The dynamics and kinematics of the coastal boundary layer off Long Island. Woods Hole, MA: Massachusetts Institute of Technology and Woods Hole Oceanographic Institution. doi: 10.1575/1912/3727

Pinkel, R., Goldin, M. A., Smith, J. A., Sun, O. M., Aja, A. A., Bui, M. N., \& Hughen, T. (2011, March). The Wirewalker: A Vertically Profiling Instrument Carrier Powered by Ocean Waves. Journal of Atmospheric and Oceanic Technology, 28(3), 426-435. doi: 10.1175/2010JTECHO805.1

Pitcher, G., Figueiras, F., Hickey, B., \& Moita, M. (2010, April). The physical oceanography of upwelling systems and the development of harmful algal blooms. Progress in Oceanography, 85(1-2), 5-32. doi: 10.1016/j.pocean.2010.02.002

Pitcher, G. C., \& Weeks, S. J. (2006, January). 7 The variability and potential for prediction of harmful algal blooms in the southern Benguela ecosystem. In V. Shannon, G. Hempel, P. Malanotte-Rizzoli, C. Moloney, \& J. Woods (Eds.), Large Marine Ecosystems (Vol. 14, pp. 125-146). Elsevier. doi: 10.1016/S1570-0461(06)80012-1

Pollard, R. (1970, August). On the generation by winds of inertial waves in the ocean. 
Deep Sea Research and Oceanographic Abstracts, 17(4), 795-812. doi: 10.1016/0011 $-7471(70) 90042-2$

Pollard, R., \& Millard, R. (1970, August). Comparison between observed and simulated wind-generated inertial oscillations. Deep Sea Research and Oceanographic Abstracts, 17(4), 813-821. doi: 10.1016/0011-7471(70)90043-4

Pollard, R. T. (1980, March). Properties of Near-Surface Inertial Oscillations. Journal of Physical Oceanography, 10(3), 385-398. doi: 10.1175/1520-0485(1980)010<0385: PONSIO $>2.0 . \mathrm{CO} ; 2$

Rainville, L., \& Pinkel, R. (2001, June). Wirewalker: An Autonomous Wave-Powered Vertical Profiler. Journal of Atmospheric and Oceanic Technology, 18(6), 1048-1051. doi: 10.1175/1520-0426(2001)018<1048:WAAWPV $>2.0 . C O ; 2$

Shchepetkin, A. F., \& McWilliams, J. C. (2005, January). The regional oceanic modeling system (ROMS): A split-explicit, free-surface, topography-following-coordinate oceanic model. Ocean Modelling, 9(4), 347-404. doi: 10.1016/j.ocemod.2004.08.002

Shearman, R. K. (2005, February). Observations of near-inertial current variability on the New England shelf. Journal of Geophysical Research: Oceans, 110(C2). doi: 10.1029/2004JC002341

Simpson, J. H., Hyder, P., Rippeth, T. P., \& Lucas, I. M. (2002, January). Forced Oscillations near the Critical Latitude for Diurnal-Inertial Resonance. Journal of Physical Oceanography, 32(1), 177-187. doi: 10.1175/1520-0485(2002)032〈0177: FONTCL $>2.0 . \mathrm{CO} ; 2$

Tintoré, J., Wang, D.-P., Garćia, E., \& Viúdez, A. (1995, June). Near-inertial motions in the coastal ocean. Journal of Marine Systems, 6(4), 301-312. doi: 10.1016/ 0924-7963(94)00030-F

Umlauf, L., \& Burchard, H. (2003, March). A generic length-scale equation for geophysical turbulence models. Journal of Marine Research, 61(2), 235-265. doi: $10.1357 / 002224003322005087$

Umlauf, L., \& Burchard, H. (2005, May). Second-order turbulence closure models for geophysical boundary layers. A review of recent work. Continental Shelf Research, 25(7), 795-827. doi: 10.1016/j.csr.2004.08.004

Williams, C., Sharples, J., Mahaffey, C., \& Rippeth, T. (2013, October). Wind-driven nutrient pulses to the subsurface chlorophyll maximum in seasonally stratified shelf seas: Wind-driven nitrate fluxes. Geophysical Research Letters, 40(20), 5467-5472. 
doi: 10.1002/2013GL058171

Xing, J., Davies, A. M., \& Fraunie, P. (2004, January). Model studies of nearinertial motion on the continental shelf off northeast Spain: A three-dimensional/twodimensional/one-dimensional model comparison study. Journal of Geophysical Research: Oceans, $109(\mathrm{C} 1)$. doi: 10.1029/2003JC001822

Xu, Z. (2002). Ellipse Parameters Conversion and Velocity Profiles for Tidal Currents in Matlab. Ocean Science Division, Fisheries and Oceans Canada. URL https://www.mathworks.com/matlabcentral/fileexchange/347. Quebec, Canada.

Zhang, X., Smith, D. C., DiMarco, S. F., \& Hetland, R. D. (2010, January). A Numerical Study of Sea-Breeze-Driven Ocean Poincare Wave Propagation and Mixing near the Critical Latitude. Journal of Physical Oceanography, 40(1), 48-66. doi: 10.1175/ 2009JPO4216.1 